NOTICE: this is the author's version of a work that was accepted for publication in Journal of Hydrology. Changes resulting from the publishing process, such as peer review, editing, corrections, structural formatting, and other quality control mechanisms may not be reflected in this document. Changes may have been made to this work since it was submitted for publication. A definitive version was subsequently published in Journal of Hydrology, Volume 464-465, September 2012, Pages 140-156, http://dx.doi.org/10.1016/j.jhydrol.2012.07.003 


\section{Decadal Rainfall Variability Modes in observed Rainfall Records over East Africa and their Relations to Historical Sea Surface Temperature Changes}

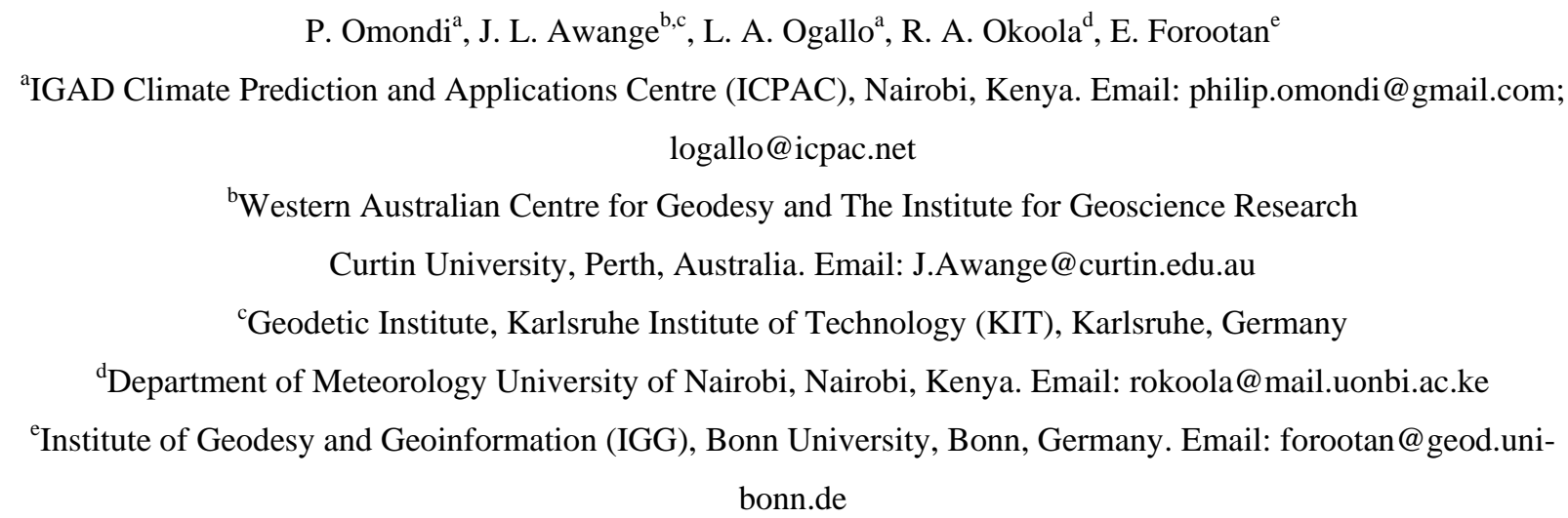

\section{Abstract}

Detailed knowledge about the long-term interface of climate and rainfall variability is essential for managing agricultural activities in Eastern African countries. To this end, the space-time patterns of decadal rainfall variability modes over East Africa and their predictability potentials using Sea Surface Temperature (SST) are investigated. The analysis includes observed rainfall data from 1920-2004 and global SSTs for the period 1950-2004. Simple correlation, trend and cyclical analyses, Principal Component Analysis (PCA) with VARIMAX rotation and Canonical Correlation Analysis (CCA) are employed. The results show decadal signals in filtered observed rainfall record with 10 years period during March - May (MAM) and October - December (OND) seasons. During June - August (JJA), however, cycles with 20 years period are common. Too much / little rainfall received in one or two years determines the general trend of the decadal mean rainfall. CCA results for MAM showed significant positive correlations between the VARIMAX-PCA of SST and the canonical component time series over the central equatorial Indian Ocean. Positive loadings were spread over the coastal and Lake Victoria regions while negative loading over the rest of the region with significant canonical correlation skills. For the JJA seasons, Atlantic SSTs had negative loadings centred on the tropical western Atlantic Ocean associated with the wet / dry regimes over western / eastern sectors. The highest canonical correlation skill between OND rainfall and the Pacific SSTs showed that El Niño-Southern Oscillation (ENSO)/La Niña phases are associated with wet/dry decades over the region.

Key words: East Africa, decadal rainfall prediction, SST, PCA, CCA, ENSO. 


\section{Introduction}

Decadal variations of extreme climate impact negatively on agricultural production resulting into massive losses amongst the affected communities and thus deleterious effect on the economy of Eastern African countries. Understanding the nature and causes of decadal fluctuations in climate system is an unresolved problem, partly because observed records are relatively short or sparse and because dynamical processes that operate on this time-scale have not firmly been understood. Over the region, much attention has been devoted to how and why precipitation varies in association with the El Niño-Southern Oscillation (ENSO) (Mutemi 2003; Indeje et.al., 2000, Ogallo 1988) at diurnal, seasonal and inter-annual time-scales. The impacts of persistent decadal climate anomalies have far reaching socio-economic implications due to persistent climate stress that they would impose on the regional socio-economic systems.

For example, decadal scale fluctuations are crucial because they control water supplies, affect biota, and may modulate higher-frequency events such as floods and droughts. Furthermore, low frequency natural variability is important in global climate change issues because it may obscure human influences on hydrological variations. Climate parameters have been observed in a global scale during the last several decades (Ryan and Bromwich, 2006; Wu and Liu, 2005, Becker et al. 2010). Examples of such variability include the North Atlantic Oscillations (NAO) phenomenon; drought in California, parts of Australia, or the Sahel and Eastern Africa. Their influences have been observed in lake level fluctuations and inter-annual rainfall records (Awange et al., 2008). Impacts of such decadal variability of extreme climate events would generally require more challenging mitigation strategies. Mitigation and adaptation to any of the climate anomalies would depend on the magnitude and duration of the persistence of the anomalies. Mitigation and/or adaptation measures are likely to involve investment in infrastructure and changes in policy due to the potentially large magnitude of their effects. 
Over Eastern Africa region, Omondi (2005), Schreck and Semazzi (2004), Nicholson (1996, 1998, 2000) have shown some evidence of decadal climate variability in the observed rainfall records. Using Climate Prediction Centre (CPC) Merged Analysis of Precipitation (CMAP) data and the Principle Component Analysis (PCA) method, Schreck and Semazzi (2004) investigated variability on the October to December (OND) rainfall over Eastern Africa region based on the period 1961-2001. They found that the most dominant mode (EOF1 explaining about 29\% of variance) to correspond to ENSO climate variability. They associated the second empirical orthogonal function (EOF2 explaining about $14 \%$ of variance) to decadal trend mode. From their results, the long-term rainfall variability was characterized by positive anomalies over the northern sector of Eastern Africa and opposite conditions over the southern sector.

Several studies in the region on inter-annual variations of East African rainfall and their possible linkages to global Sea Surface Temperature (SST) changes have been undertaken (e.g., Indeje et al., 2000; Mutemi, 2003; Mutai 2003; Owiti, 2005; Nyakwada 2009). The main focus of these studies were especially on the relation between rainfall anomalies and SST perturbations over the equatorial Pacific and Indian Ocean basins, and to some extent, the Atlantic Ocean (Ogallo et al, 1988; Nicholson and Entekhabi, 1987; Mutai and Ward, 2000; Indeje et al., 2000; Saji et al., 1999; and Goddard and Graham 1999). These studies determine the dominant role played by the ENSO anomaly patterns in influencing the inter-annual variabilities of the equatorial East Africa rainfall (Ogallo et al, 1988; Indeje et al., 2000). Note that the zonal temperature gradient over the equatorial Indian Ocean, often referred to as the Indian Ocean Dipole Mode (IOD) (Saji et al., 2003a and 2003b), therefore, the coupled IOD-ENSO influence have also been linked to some of the wettest periods in the region, such as rainfalls in 1961 and 2006 (Black et al., 2003; Black, 2004; Bowden and Semazzi, 2007). 
In this paper, we present attempts made to examine decadal trend mode in observed East Africa rainfall records and its possible linkage to decadal patterns of global SST records. Our investigation extends the previous studies by considering a relatively longer period of rainfall data from 1920-2004 and global SSTs for the period 1950-2004 and studying their interactions within their overlap periods. We made use of advanced multivariate statistical analysis techniques such as VARIMAX-PCA and Canonical Correlation Analysis (CCA) which allow an in-depth investigation of possible correlations between decadal SST and rainfall variations.

The remainder of the paper is organized as follows: In the next section, we briefly describe the data and method used in the study. The trend results are presented in Section 3. Section 4 and 5 summarize the main decadal patterns of rainfall and SST variabilities. The link between SSTs and decadal rainfall patterns over the region is discussed in Section 6. Section 7 gives a summary, the major findings and conclusion of the study.

\section{Data and methods}

\subsection{Data}

In this analysis, monthly observed rainfall data was obtained from IGAD Climate Prediction and Applications Centre (ICPAC), the Kenya Meteorological Department (KMD), Tanzania Meteorological Agency (TMA) and Uganda Meteorological Department (UMD). The observed monthly rainfall data used are from 37 stations (Figure 1) unevenly distributed over East Africa (Omondi 2005). Also used in the study are reconstructed Reynolds SST data for the period 1950 to 2004 obtained from the United States (US) National Oceanic and Atmospheric Administration (NOAA) official website ${ }^{1}$. The data are archived as the optimum interpolation (OI), version 2 , global SST values on $1^{\circ}$ by $1^{\circ}$ grid points. The SST values include in-situ and satellite SSTs

\section{http://www.esrl.noaa.gov/psd/data/gridded/data.ncep.oisst.v2.html}


observations plus those SSTs that are simulated by sea-ice cover. More on the SST data can be obtained from Reynolds and Marsico 1993, Reynolds and Smith 1994, and Reynolds et al. 2002.

\subsection{Method}

Since our attention is primarily on the lower frequency (long wave-length) variabilities, a 9-point binomial coefficient filter is employed to smooth both the rainfall and SST time series so that all fluctuations of period shorter than 10 years are considerably suppressed. A Graphical method is then used to extract decadal trend modes while Mann-Kendall and the Spearman rank tests statistical methods that are based on rank statistics (Kendall 1976; Kendall and Stuart 1961; WMO 1966) were employed to test the significance of the observed trends.

The PCA method is a statistical signal extraction technique based on diagonalization of the autocovariance or auto-correlation matrix of a data set (Wilks, 1995). In this study, the VARIMAX rotated version of PCA was applied to define dominant modes of variability of the low passed rainfall and SST series. The VARIMAX rotation is selected to improve the physical interpretation of the PCA modes and to derive more localized components (see, e.g., Richman, 1986). To define the relationship between the dominant modes of decadal rainfall variabilities and SST variations in the global oceans, the Canonical Correlation Analysis (CCA) technique was adopted. Unlike PCA, CCA is a statistical technique that identifies a sequence of pairs of patterns in two multivariate data sets and constructs sets of transformed variables by projecting the original data onto these patterns (Barnett and Preisendorfer (1987); Wilks (1995); Barnston and He (1996); Von Storch and Zwiers (1999); and Mutemi (2003)). CCA, therefore, can be regarded as a multivariate statistical technique that calculates linear combinations of a set of predictors that maximizes relationships, in a least square sense, to the similarly calculated linear combinations of a set of predictand. The patterns are chosen such that new variables defined by projection of the two data sets onto these patterns exhibit maximum correlation but are 
uncorrelated with the projections of the data onto any of the other identified patterns. The superiority of CCA over other several techniques is its ability to operate on full fields of information and to objectively define the most highly related patterns of predictor and predictand (Barnett and Preisendorfer 1987; Indenje et al., 2000; Mutemi 2003; Omondi 2005; Nyakwada 2009).

Canonical Correlation Analysis (CCA) goes beyond the limitation of the simple correlation analysis by taking into consideration the full space and time dimensions of the fields analyzed and this is an exceptional skill capability of the technique. It also gives an extensive set of diagnostics that offer some insight into the physical base of the relationships used to form the predictions. The advantages of CCA include ability to operate on full fields of information and to objectively define the most highly related pattern of predictors and predictands. Its capability to define both the space and time evolution of the predictor dataset that best predicts an associated pattern of a predictand is efficient compared to simple correlation technique.

In this study, CCA was used to select pairs of spatial patterns of the two space / time dependent variable sets (VRIMAX-PCA of rainfall data and SSTs) such that the (time dependent) pattern amplitudes are optimally correlated. The strength and the sign of the corresponding patterns are described by the canonical correlation coordinates. Since the canonical series are normalized to unit variance, the canonical correlation patterns are expressed in the units of the variable they represent and indicate the "typical" strength of the mode of covariation described by the patterns. The correlation between the canonical coordinates measures the degree of association between the canonical patterns of predictor and predictand variables ( Xoplaki et al., 2003). 
$158 v_{m}=a_{m}^{T} x^{\prime}=\sum_{i=1}^{I} a_{m, i} x^{\prime}, \mathrm{m}=1, \ldots, \min (\mathrm{I}, \mathrm{J})$

and

$160 \quad w_{m}=b_{m}^{T} y^{\prime}=\sum_{j=1}^{J} b_{m, j} y^{\prime}, \mathrm{m}=1, \ldots, \min (\mathrm{I}, \mathrm{J})$

161 This construction of canonical variates is similar to that of the principal components $u_{m}$, in that each is a linear combination of (a sort of weighted average) of elements of the respective data vectors $x^{\prime}$ and $y^{\prime}$. These vectors of weights, $a_{m}$ and $b_{m}$, are called the canonical vectors. One data- and canonical-vector pair need not to have the same dimension as the other. Therefore, in Equations 1a, vectors $x^{\prime}$ and $a_{m}$ each have $I$ elements, while those of $y^{\prime}$ and $b_{m}$ in Equation $1 \mathrm{~b}$ have $J$ elements each. $m$ is the number of canonical pairs, so called 'canonical variates' that can be extracted from the two data sets. In practice, $\mathrm{m}$ is derived as $\mathrm{m}=\min (I, J)$.

$\operatorname{corr}\left[v_{k}, w_{m}\right]=\left\{\begin{array}{l}r_{c_{m}}, k=m \\ 0, k \neq m\end{array} ;\right.$

$\operatorname{Var}\left[\mathcal{V}_{m}\right]=a_{m}^{T}\left[S_{x, x}\right] a_{m}=\operatorname{Var}\left[\boldsymbol{W}_{m}\right]=b_{m}^{T}\left[S_{y, y}\right] b_{m}=1$,

174 Equation 2a shows that each of the $m$ successive pairs of canonical variates exhibits no greater correlation than the previous pair. These correlations between the pairs of canonical are called 
the canonical correlations, $\boldsymbol{r}_{C}$. Equation $2 \mathrm{~b}$ states that each canonical variate is uncorrelated with all of the other canonical variates except its specific counterpart in the $m^{\text {th }}$ pair. Finally, Equation $2 \mathrm{c}$ states that each canonical variate has unit variance.

\section{Results of the Decadal Trend Modes}

Some examples of patterns of the decadal rainfall trend for both the smoothed and unsmoothed time series obtained are shown in Figure $2 \mathrm{a}$ and Figure $2 \mathrm{~b}$ associated with the long rainy season of March-May (MAM). The ten year cycles are clearly discernible in the smoothed series. These modes are better illustrated when the time series of smoothed series are plotted as anomalies in Figure $3 \mathrm{a}$ and Figure $3 \mathrm{~b}$. The trend mode for the third short rainfall season associated with JuneAugust (JJA) rainfall shows that western and coastal parts of the region receive substantial amount of rainfall, which unlike MAM and OND seasons, are dominated by twenty years cycles (Figure 3b). The major decadal signals observed from the graphs indicated that for MAM seasons, the wet decades were 1921-1930, 1961-1970 and the late 1981-90 while the dry ones included 1931-1940, 1941-1950, 1951-1960, early parts of 1971-1980 and 1991-2000. inland water bodies and complexity in the East Africa topography.

There were significant spatial variations in the observed decadal trend signals, with no noticeable decade with one specific dominant trend over the whole region. This could be attributed to the influence of regional and local factors including the existence of many large

The short rainfall season of OND is the second major rain season for the region. The extreme events in one or two years within a decade influenced the general trend of the decadal mean rainfall. Example is the 1997/98 El Niño related floods that made 1991-2000 be a wet decade in most zones. The 1961/1970 decade was wet due to the heavy rainfall that was received over 
most parts of the region in 1961/1962 that resulted into the rise of Lake Victoria level by over 2.5 meters (Yin and Nicholson, 1998, Nicholson, 1998, Phoon et al., 2004).

The major decadal signals observed for OND seasons were wet decades of the late 1941-1950, the early 1961-1970, the early 1981-1990 and 1991-2000 while the dry ones included 19211930, 1931-1940, early part of 1951-1960 and 1971-1980 (Figure 4 ). For the JJA seasons, the major decadal variability was relatively longer than ten years. The wet decades included 19411950, 1951-1960, 1981-1990, 1991-2000 while the dry ones included 1921-1930, 1931-1940, 1961-1970, 1971-1980 for the western parts of the region (Figure 4). The scenario was exactly opposite along the coastal region, i.e., the wet decades were generally 1921-1930, 1931-1940, 1961-1970, 1971-1980 while the dry decades were 1941-1950, 1951-1960, 1981- 1990, 19912000. There was significant spatial variation in the observed trends (Figure 4).

In order to establish whether the observed decadal trend and cyclic modes are significant, statistical tests on the differences amongst some decadal means and the Spearman rank were carried out (Maritz, 1981). A comparison of decadal means and with the long-term seasonal rainfall means showed that the decades of 1921-1930 and 1961-1970 were generally wet while 1931-1940, 1951-1960 and 1991-2000 were generally dry during the long rainfall (MAM) seasons of the study period. In order to establish whether there was existence of any spatially coherent decadal differences, the spatial patterns of the various means were plotted in Figure 4. Large scale wet / dry cases were, however, evident for a few specific years. Similar to the MAM seasons as already stated, this could have been due to the influence of regional and local factors, e.g., including the existence of many large inland water bodies and topographical complexity in the region (Mukabana and Pielke 1996; Anyah 2005). 
225 The VARIMAX-PCA method was applied on OND rainfall time series. According to the Scree,

226 Kaiser's criterion and North et al. (1982) sampling errors tests, the first five modes accounting

227 for $81.3 \%$ of total OND rainfall variance are statistically significant (see Table 1 and Figure 5).

228 For brevity, here, we only show the first 3 dominant modes of OND seasons in Figure 6. The

229 first mode is extended nearly in all parts of the region except the south-eastern segment of 230 Tanzania. Schreck and Semazzi (2004) also found a remarkably similar distribution of EOF 231 loadings, although their analysis covered slightly a bigger domain. The variance in EOF1 of 232 Schreck and Semmazi (2004) was 28\%, compared with $15.9 \%$ of our corresponding mode. This 233 difference may be attributed to the larger region covered by their analysis. The corresponding 234 PC time series (Figure 6 (b)) indicates some consistence with ENSO variability (so called `cold 235 ENSO' signal in Ogallo et al. (1988) and Indeje et al. (2000)). According to PC1, the average cold ENSO events were pronounced in the decades 1980-1990 and this brought about general depressed rainfall in the region corresponding to the high peaks of the time series. The reverse condition is represented by PC2 in Figure 6(b) with a dipole spatial pattern over the region. The third mode is related to the decadal trend mode (Bowden and Semazzi, 2007), showing positive mode over the north and south of Lake Victoria and a decrease mainly over the eastern coastal regions (Figure $6(\mathrm{c})$ ). 


\subsection{VARIMAX-PCA of MAM rainfall}

244 We also applied VARIMAX-PCA on MAM rainfall seasons. Results of the Scree and North et al. (1982) test show that the first six modes accounting for about $80 \%$ of variance are statistically significant (see Table 2 and Figure 7). Like in the previous section, we only show the first three dominant modes. Mode one (EOF1 and PC1) depicts the north-south rainfall dipole brought about by the movement of the Sun from one hemisphere to the other i.e. due to the Inter-Tropical Convergence Zone (ITCZ), while the second mode was related to the positive IOD mode and the decadal trend in EOF3 and PC3 (Figure 8).

\subsection{VARIMAX-PCA of JJA rainfall}

252

Implementing VARIMAX-PCA on JJA seasons show that parts of the equatorial sector, covering northern Tanzania, western parts of East Africa and the coastal areas generally get rains. Figure 9 and Table 3 indicate that seven PCA modes, accounting for about $93 \%$ of the total JJA variance, were significant.

Figure 10(a) displays the spatial pattern for the Eastern Africa region in which EOF 1 explains $28.6 \%$ of the total JJA variance. The distribution of the loadings is characterised by moisture incursion from the Congo air basin causing wetness in the western sector of the region (Nyakwada 2010). The corresponding time series (Figure 10(b) exhibits both strong inter-annual variability and low-frequency background variability. The evolution of the background variability has positive trend in 1980/1990 decade which reached its highest levels during the early 1998. There is indication of subsequent decline in the amplitude during the late 1990s and early 2000. Combined interpretation of the Regional-EOF1 distribution of loadings (Figure 10(a)) and the corresponding time series suggests that the western sector of Eastern Africa had $1980 / 1990$ decade wet while the southern sector drier. The southern sector during this season is usually dry and this could have resulted into the negative anomalies.

\section{Results for S-mode VARIMAX-PCA analysis for the specific basins' SST anomalies}


This section presents the results of implementing the VARIMAX-PCA method on the SST records of some specific oceanic basins during OND, JJA and MAM seasons in order to compare the SST behaviours of these oceanic basins with the rainfall patterns over East Africa. The derived VARIMAX solutions are summarized in Table 4 and the derived spatial patterns are shown in Figure 11. The first mode of VARIMAX-PCA derived from decadal SST of the Indian Ocean during OND seasons accounts for $38 \%$ of the total variance of SST. The positive loading is centred on the tropical equatorial Indian Ocean and the negative centre is located over the south-western Indian Ocean (Figure 11 (a)). The Indian Ocean EOF 1 for MAM (Figure 11(c)), however, had a dipole structure like pattern of SSTs with positive centre near the Indo-Pacific area while negative centre located near the south-western Indian Ocean. The total variance accounted for this mode is $45.4 \%$ (Table 4 ).

Figure 12 (a) shows the spatial patterns for Atlantic Ocean during the same OND seasons. Generally, the equatorial basin of Atlantic shows positive loadings while its northern sector exhibits negative loadings with the highest variance of $64.1 \%$ during OND season. It is noteworthy that the OND season had the first and second variances taking nearly all the total variances (Table 4). In other seasons, three variances explained nearly the total variances. This could be attributed to the strong and alternating north-south dipole pattern reflecting the known patterns of the Atlantic Tropical Dipole Oscillation (Chang and Li, 1997). In the Pacific Ocean, the first dominant mode for the four seasons seems to have positive / negative loadings over equatorial eastern / western ocean basin regions (Figure 13) that seem to reflect the ENSO variability mode (Ogallo et al., 1988; Indeje et al., 2000; Mutemi, 2003; Owiti, 2005). This dipole structure like pattern of SSTs has negative centre near the Indo-Pacific area while the positive centre was located near the eastern equatorial Pacific Ocean. 
The results seem to reflect the El Niño / La Niña variability mode (Tanimoto et al, 1993; Trenberth and Hurrel, 1994 and Mantua et al, 1997).

\section{Results from canonical correlation analysis (CCA)}

295

In this section, the strength and the sign of the corresponding patterns are described by the canonical correlation coordinates. The CCA method takes into account analysis of the full space and time dimensions of the two fields (rainfall and SSTs) which make it superior comparing to a conventional correlation analysis.

\subsection{CCA results for MAM rainfall seasons}

The average December-February (DJF), JJA and MAM SSTs from the various ocean basins were independently correlated with MAM rainfall time series. MAM is the major rainfall season for the region and the skill of its predictability is still very low. Three significant modes were discernible for the Indian Ocean basin with DJF and MAM SSTs. The canonical modes accounting for about $72 \%$ and $86.8 \%$ respectively of the total variance were selected as inputs into the CCA model. Figures 14 and 15 give examples of the CCA loading patterns for the DJF and MAM SSTs of the Indian Ocean respectively. An area of high significant positive correlation between the mentioned SSTs and the canonical component time series was evident over the central equatorial Indian Ocean (Figure 14 (a)). Similarly, there was significant correlation at most locations with positive loadings over the coastal and Lake Victoria regions and a negative loading over the rest of the region (Figure 14 (b)). The canonical correlation skill between rainfall and the predictor SST modes was about -0.79 (Figure 14 (c)). The canonical correlation score between rainfall and the predictor SST modes was 0.72 and 0.96 for one and zero lags, respectively. The canonical scores of the pattern with warm SST in the Indian Ocean were increasing since the mid 1970s whereas the negative coupling was decreasing. Power et al., (1998) in his analysis of decadal climate variability showed that decadal variability in Indian Ocean SST south of $40^{\circ}$ is associated with rainfall variability over East Australia. 
The averages of MAM and JJA SSTs from the various ocean basins were independently correlated with JJA rainfall. Figures 16 and 17 depict loading patterns for the MAM and JJA SSTs of the Atlantic Ocean with JJA seasonal rainfall modes together with the corresponding temporal functions respectively. The negative loadings over the equatorial north-western and central Atlantic Ocean regions (Figure 16(a) are associated with the wet/dry regimes over western/eastern sectors of Eastern Africa (Figure 16b). The canonical correlation score between rainfall and the predictor SST modes was 0.72 for lag one and 0.87 for zero lag. Lag zero that had maximum weights over the Atlantic Ocean basin and was positively correlated with JJA over the whole of western and coastal regions of Kenya together with Uganda (Figure 17b). Similar results have been derived by previous studies, including those of Preston (2005), Washington et al., (2003), Reason et al., (2004) over the Indian Ocean and South African rainfall.

\subsection{Results for October - December rainfall season}

The average JJA and OND SSTs from the various ocean basins were independently correlated with OND rainfall. Figures 18 and 19 represent CCA loading patterns for JJA and OND of the Pacific Ocean SSTs and OND rainfall respectively. The highly negative loading over the equatorial eastern Pacific Ocean seems to be the major mode associated with the wetness in nearly whole part of the region with pocket of dryness conditions over southern parts that generally have unimodal rainfall regimes. The canonical correlation skill between OND rainfall and the predictor SST modes was 0.88 at lag one showing stronger influence of eastern Pacific to the region.

Figure 19 shows the CCA loading patterns for the OND rainfall and predictor of the Pacific 
342 Ocean is linked to the generally dry conditions in the region. The canonical correlation skill between OND decadal rainfall and the predictor SST modes is 0.97. Thus cold ENSO phase would be associated with depressed rainfall season over the whole region, while warm phase (El Niño) would be associated with enhanced decadal rainfall over most parts of the region.

\section{Summary and Conclusion}

This study has provided some evidence of decadal variability in the inter-annual patterns of East Africa rainfall. The MAM and OND seasonal rainfall are dominated by 10 year cycles of wet and dry phases, while the JJA season showed a 20 years cycle of wet and dry phases. Some teleconnections were also evident between the observed decadal rainfall variability patterns and SST variability modes over parts of the global oceans. The significant correlation between the rainfall and SSTs offers a useful indicator in predicting rainfall of the region at decadal time scale. Specifically, the study has shown that:

1. Trend analysis results showed that although no significant trend in the inter-annual patterns were discernible at many locations, too much or too little rainfall received in one or two years influenced the general trend of the decadal mean rainfall. Eight and one zones in OND and MAM showed significant positive trends during this period of study, respectively. For the JJA season, when only the western and coastal parts of the region receive substantial amount of rainfall, no significant trends were observed although the decades after 1961 were wetter than before in these western regions but drier along the coastal regions. No decade was observed to have the whole region dominated by one specific trend mode during the period of study except 1931-1940 and 1961-1970 during OND seasons.

2. Results from CCA, applied independently on the average DJF and MAM SSTs from the various ocean basins and MAM rainfall, show that three significant modes were discernible. One area of high significant positive correlation between the SSTs and the 
canonical component time series was evident over the central equatorial Indian Ocean. Similarly, there was significant correlation resulting into wet coastal and Lake Victoria regions with the rest of the region found out to be dry.

3. The results from the average MAM and JJA SSTs correlated with JJA rainfall had negative loadings centred on the equatorial western and central Atlantic Ocean regions 
382 Acknowledgement: This work was performed while Philip Omondi was based at the IGAD 383 Climate Prediction and Application Centre - Nairobi (ICPAC). J.L. Awange acknowledges the 384 financial support of the Alexander von Humbodlt Foundation (Ludwig Leichhardt's Memorial 385 Fellowship), The Institute for Geoscience Research (TIGeR), and a Curtin Research Fellowship. $386 \mathrm{He}$ is grateful for the warm welcome and the conducive working atmosphere provided by his 387 host Prof. Heck at the Geodetic Institute, Karlsruhe Institute of Technology (KIT). This is a 388 TIGeR publication No. ??? 


\section{References}

1http://www.esrl.noaa.gov/psd/data/gridded/data.noaa.oisst.v2.html, accessed date: November 2011.

Awange, J.L., Ogalo, L., Bae, K.H., Were, P., Omondi, P., Omute, P., and mullo, M. (2008). Falling Lake Victoria water levels: is climate a contributing factor? pp. 1-20, DOI: 10.1007/s10584-008-9409-X.

Anyah, R. O, 2005: Modelling the variability of the climate system over Lake Victoria basin: PhD. thesis, Department of Marine, Earth and Atmospheric Sciences, North Carolina University, USA.

Barnett, T.P. and R. Preisendorfer, 1987: Origins and levels of monthly and seasonal forecast skill for United States surface air temperatures determined by canonical correlation analysis. Mon. Wea. Rev., 115, 1825-1850.

Barnston, A.G. and C.F. Ropelewski, 1992: Prediction of ENSO episodes using canonical correlation analysis. J. Climate, 5, 1316-1345.

Barnston, A.G., 1994: Linear statistical short-term climate predictive skill in the Northern Hemisphere. J. Climate, 7, 1513-1564.

Barnston, A.G.and Y. He, 1996: Skill of CCA forecasts of 3-month mean surface climate in Hawaii and Alaska. J. Climate, 9, 2579-2605.

Birkett, C.M. (1994). Radara altimetry: new concept in monitoring lake level changes. EOS, 75, pp. 273 275. DOI: 10.1029/94EO00944.

Black, E, J. Slingo and K. R. Sperber, 2003: An observational study of the relationship between excessively strong short rains in the coastal East Africa and Indian Ocean SST., Mon Wea. Rev. $131,74-94$.

Black, E., 2004: The relationship between Indian Ocean sea-surface temperature and East African rainfall, Phil. Trans. R. Soc. A 2005 363, 43-47, DOI: 10.1098/rsta.2004.1474

Bowden, J. and F. H. M. Semazzi, 2007: Empirical analysis of intraseasonal climate variability over the Greater Horn of Africa. J. Climate 20 (23) 5715-5731

Chang, P., L. Ji, and H. Li, 1997: A decadal climate variation in the tropical Atlantic Ocean from thermodynamic air-sea interactions. Nature 385, 516-518.

Chateld, C. (1989). The analysis of time series: an introduction (Chapman and Hall), pp. ISBN-10: 1584883170 .

Dumont, H.J. (1998). The Caspian Lake: history, biota, structure, and function. Limnnology and Oceanography 43, pp. 44-52. ISSN: 0024-3590.

Dumont, H.J., Tamara, A., Shiganova, U.N. (2004). Aquatic invasions in the Black, Caspian, and Mediterranean Seas (Nato Science Series). Kluwer Academic Publishers, 313 pp. ISBN-10: 140201869X.

Graham, N.E., J. Michaelsen and T. Barnett, 1987a: An investigation of the El Niño-Southern Oscillation cycle with statistical models. 1. Predictor field characteristics. J. Geophys. Res., 92, 14251-14270.

Graham, N.E., J. Machaelsen and T. Barnett, 1987b: An investigation of the El Niño-Southern Oscillation cycle with statistical models. 2. Model results. J. Geophys. Res., 92, 14271-14289. 
Goddard, L. and N. E. Graham, 1999: The importance of the Indian Ocean for simulating Rainfall Anomalies over Eastern and Southern Africa, J Geophys Res, 104, 19099-19116.

Indeje, M., F. H. M. Semazzi, and L. J. Ogallo, 2000: ENSO signals in East African rainfall and their prediction potentials. Int. J. Climatol. 20, 19-46.

Kendall, M. G., 1938: A new measure of rank correlation. Biometeorology. 33: 81-93.

Kendall, M. G., 1945: The treatment of ties in ranking problems. Biometeorology. 33: 297-298

Kendall, M. G., 1948: Rank correlation Methods. London: Charles Griffin.

Kendall, M. G., 1976: Time Series. Charles Griffin, London

Kendall, M. G., and A. Stuart, 1961: Advanced theory of Statistics. Charles Griffins, London

Livezey, R. and T. Smith 1999b: Co variability of aspects of North American climate

Mantua, N. J., S. R. Hare, Y. Zhang, J. M. Wallace, and R. C Francis, 1997; A pacific interdecadal climate oscillation with impacts on salmon production. Bull. Amer. Meteor. Soc. 78, 1069-1079.

Maritz. J.S. (1981). Distribution-Free Statistical Methods, Chapman \& Hall, 217 pp. ISBN 0-412-159406.

Mukabana, J.R., and R.A. Pielke, 1996: Investigating the influence of synoptic scale winds and mesoscale circulations and diurnal weather patterns over Kenya using a mesoscale numerical model. Mon Wea Rev., 124: 224-243.

Mutemi, J. N, 2003: Climate anomalies over eastern Africa associated with various ENSO evolution phases: Ph.D. Thesis, University of Nairobi, Kenya.

Nicholson, S.E. and Entekhabi, D., 1987: Rainfall variability in equatorial and Southern Africa: Relationships with sea-surface temperature along the southwestern coast of Africa. J. Climate and Appl. Meteorol., 26, pp.561-578

Nicholson, S.E., 1998: Historical fluctuations of Lake Victoria and other Lakes in the Northern Rift valley of East Africa. J. T Lehman (ed.), Environmental Change and Response in East Africa Lakes, Kluwer Academic Publishers: Netherlands, pp. 7-35.

North, G.R., Bell, T.L and Cahalan, R.F 1982: 'Sampling errors in estimation of empirical orthogonal functions', A. Meteorol. Soc., 110, 699-706

Nyakwada, W., 2009: Predictability of East African Seasonal Rainfall with Sea Surface Temperature Gradient Modes: Ph.D. Dissertation, Dept. of Met: University of Nairobi.

Ogallo, L. J., 1988: Relationships between seasonal rainfall in East Africa and the Southern Oscillation. J. Climatol., 8, $31-43$

Ogallo, L. J., J. E. Janowiak, and M. S. Halpert, 1988: Teleconnection between seasonal rainfall over Eastern Africa and Global Sea surface temperature anomalies. J. Meteor. Soc., Japan, 66, 807 822 
Omondi P. A., 2005: Potential causes and predictability of the space - time patterns of the decadal rainfall variability modes over east Africa. MSc Thesis, Department of Meteorology, University of Nairobi

Owiti, O. Z., 2005: Use of the Indian Ocean Dipole indices as predictor east African rainfall anomalies. MSc Thesis, Department Of Meteorology, University of Nairobi.

Phoon, S. Y., Shamseldin, A.Y., and Vairavamoorthy, K. (2004). "Assessing impacts of climate change on Lake Victoria Basin, Africa." People-Centred Approaches to Water and Environmental Sanitation, 30th WEDC International Conference, Vientiane, Lao PDR.

Preston, A., 2005: Southern African rainfall variability and Indian Ocean Sea surface temperatures: an observational and modelling study (Cape Town: Oxford University Press).

Power, S., T. Casey, C. Folland, A. Colman, and V.M. Mehta, 1998: Interdecadal modulation of the impact of ENSO on Australia. Climate Dyn, 15, 319-324.

Reason, C. J. C., Allan, R. J., Lindesay J. A. and Ansel T. A., 2000: ENSO and Climate signals across the Indian Ocean basin in global context. Int. Jr. of Climatol., 20, 1285-1327.

Reynolds, R.W., and D.C. Marsico, 1993: An improved real-time global sea surface temperature analysis. J. Climate, 6, 114-119.

Reynolds, R. W., and T. M. Smith, 1994: Improved global sea surface temperature analyses using optimum interpolation. J. Climate, 7, 929948.

Reynolds, R.W., N.A. Rayne, T.M. Smith, D.C. Stokes, and W. Wang, 2002: An Improved In Situ and Satellite SST Analysis for Climate, J. Climate, 15, 1609-1625.

Richman, M.B. (1986): Review Article: Rotation of principal components. J. climat., 6, 293-335.

Saji, N. H., Goswani, B. N., Vinayachandran, P.N., Yamagata, T., 1999: A dipole mode in the tropical Indian Ocean, Nature, 401, p. 360-363.

Saji, N. H., and T. Yamagata 2003a: Possible impacts of Indian Ocean dipole events on global climate, Clim. Res., 25, 151-169.

Saji, N. H., and T. Yamagata, 2003b: Interference of teleconnection patterns generated from the tropical Indian and Pacific Oceans. Climate Res., 25, 151-169.

Schreck, J. C and F. H. M. Semazzi, 2004: Variability of the recent climate of Eastern Africa. Int. J. Climatol. 24, $681-701$.

Tanimoto, Y., N. Iwasaka, K. Hanawa, and Y. Toba, 1993; Characteristic variations of sea surface temperature with multiple time scales in the North Pacific; J. Climate 6, 1153-1160.

Trenberth, K. E. and J. W. Hurrel, 1994: Decadal atmosphere-ocean variations in the Pacific: Climate Dyn. 9, 303-319.

Von Storch, H. and F. Zwiers, 1999: Statistical analysis in climate research; Cambridge University Press.

Washington, R., Preston, A., and Todd, M.C. (2003): The role of Indian and Pacific Ocean SSTs in African rainfall variability: Bulletin of the American Meteorological Society 84(7). pp. 899-900. 
529 Wilks, D. S., 1995: Statistical methods in the atmospheric sciences: Academic press, pp 45-50, 399-402.

530 WMO, 1966: Climate change. WMO Tech. Note No. 79, Geneva: WMO.

Xoplaki, E., J. Gonzalez-Rouco, D. Gyalistras, J. Luterbacher, R. Rickli, and H. Wanner, 2003: Interannual summer air temperature variability over Greece and its connection to the large-scale atmospheric circulation and Mediterranean SSTs 1950-1999. Clim. Dyn. 20, 537-554.

Yin, X and Nicholson, S. E. (1998): The water balance of Lake Victoria. J. of Hydrol. Sciences. Vol. 43, Issue 5, pp. 789-811. 
Tables

540 Table 1: Eigenvalues, variance and accumulated variance extracted by each mode of the decadal 541 OND rainfall

\begin{tabular}{|c|c|c|c|c|}
\hline PERIOD & FACTOR & EIGENVALUE & $\begin{array}{l}\text { VARIANCE } \\
\text { EXTRACTED (\%) }\end{array}$ & $\begin{array}{l}\text { CUMMULATIVE } \\
\text { VARIANCE (\%) }\end{array}$ \\
\hline \multirow{3}{*}{ OND } & 1 & 15.9 & 42.9 & 42.9 \\
\cline { 2 - 6 } & 2 & 5.3 & 14.2 & 57.1 \\
\cline { 2 - 6 } & 3 & 3.9 & 10.5 & 67.6 \\
\cline { 2 - 6 } & 4 & 2.7 & 7.2 & 84.8 \\
\cline { 2 - 6 } & 5 & 2.4 & 6.5 & 81.3 \\
\hline
\end{tabular}

542

Table 2: Eigenvalues, variance and accumulated variance extracted by each mode of the decadal 544 MAM rainfall

\begin{tabular}{|c|c|c|c|c|}
\hline PERIOD & FACTOR & EIGENVALUE & $\begin{array}{l}\text { VARIANCE } \\
\text { EXTRACTED (\%) }\end{array}$ & $\begin{array}{l}\text { CUMULATIVE } \\
\text { VARIANCE (\%) }\end{array}$ \\
\hline \multirow{3}{*}{ MAM } & 1 & 7.3 & 19.7 & 19.7 \\
\cline { 2 - 5 } & 2 & 6.9 & 18.6 & 38.3 \\
\cline { 2 - 5 } & 3 & 5.9 & 15.9 & 54.2 \\
\cline { 2 - 5 } & 4 & 4.2 & 11.4 & 65.6 \\
\cline { 2 - 5 } & 5 & 3.0 & 8.1 & 73.6 \\
\cline { 2 - 5 } & 6 & 2.3 & 6.3 & 80.0 \\
\hline
\end{tabular}


546 Table 3: Eigenvalues, variance and accumulated variance extracted by each mode of the decadal 547 JJA rainfall

\begin{tabular}{|c|c|c|c|c|}
\hline PERIOD & FACTOR & EIGENVALUE & $\begin{array}{l}\text { VARIANCE } \\
\text { EXTRACTED (\%) }\end{array}$ & $\begin{array}{l}\text { CUMULATIVE } \\
\text { VARIANCE (\%) }\end{array}$ \\
\hline \multirow{3}{*}{ JJA } & 1 & 15.8 & 28.6 & 28.6 \\
\cline { 2 - 5 } & 2 & 14.6 & 26.6 & 55.2 \\
\cline { 2 - 5 } & 3 & 11.4 & 20.7 & 75.9 \\
\cline { 2 - 5 } & 4 & 2.9 & 5.4 & 81.3 \\
\cline { 2 - 5 } & 5 & 2.8 & 5.1 & 86.4 \\
\cline { 2 - 5 } & 6 & 2.5 & 4.6 & 91.0 \\
\cline { 2 - 5 } & 7 & 1.2 & 2.2 & 93.2 \\
\hline
\end{tabular}


Table 4: Percentage variance extracted by the first 4 RPCs of decadal SST

\begin{tabular}{|c|c|c|c|c|c|}
\hline & & OND & DJF & $\overline{M A M}$ & JJA \\
\hline \multirow{4}{*}{$\begin{array}{l}\text { Indian } \\
\text { Ocean }\end{array}$} & PC1 & 38.0 & 40.5 & 45.4 & 35.2 \\
\hline & PC2 & 26.0 & 15.8 & 41.4 & 32.5 \\
\hline & PC3 & 20.1 & 15.7 & & 24.9 \\
\hline & PC4 & 11.3 & 8.5 & & \\
\hline Total Variance & & 95.4 & 80.5 & 89.8 & 92.6 \\
\hline \multirow{4}{*}{ Atlantic Ocean } & PC1 & 64.1 & 39.1 & 32.5 & 39.7 \\
\hline & PC2 & 34.9 & 30.6 & 31.5 & 34.9 \\
\hline & PC3 & & 13.7 & 21.8 & 13.5 \\
\hline & PC4 & & & & \\
\hline Total Variance & & 99.0 & 83.4 & 85.8 & 88.1 \\
\hline \multirow{4}{*}{$\begin{array}{l}\text { Pacific } \\
\text { Ocean }\end{array}$} & PC1 & 31.0 & 40.1 & 40.9 & 32.0 \\
\hline & PC2 & 23.4 & 30.0 & 28.2 & 23.7 \\
\hline & PC3 & 22.9 & 11.5 & 9.6 & 23.5 \\
\hline & PC4 & 10.3 & & & \\
\hline Total Variance & & 76.6 & 81.6 & 78.7 & 79.2 \\
\hline
\end{tabular}




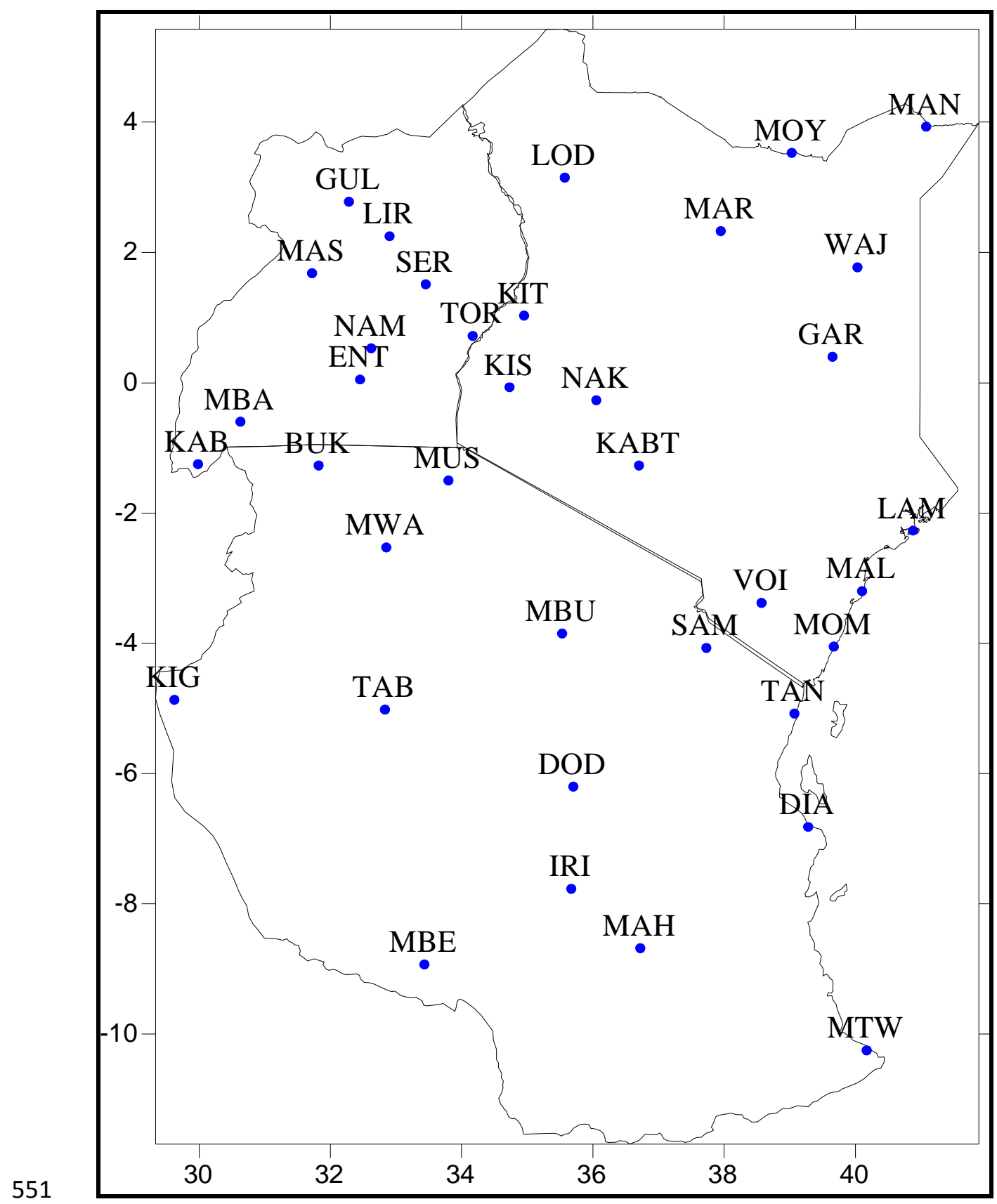

Figure 1: Distribution of representative stations over the study region 


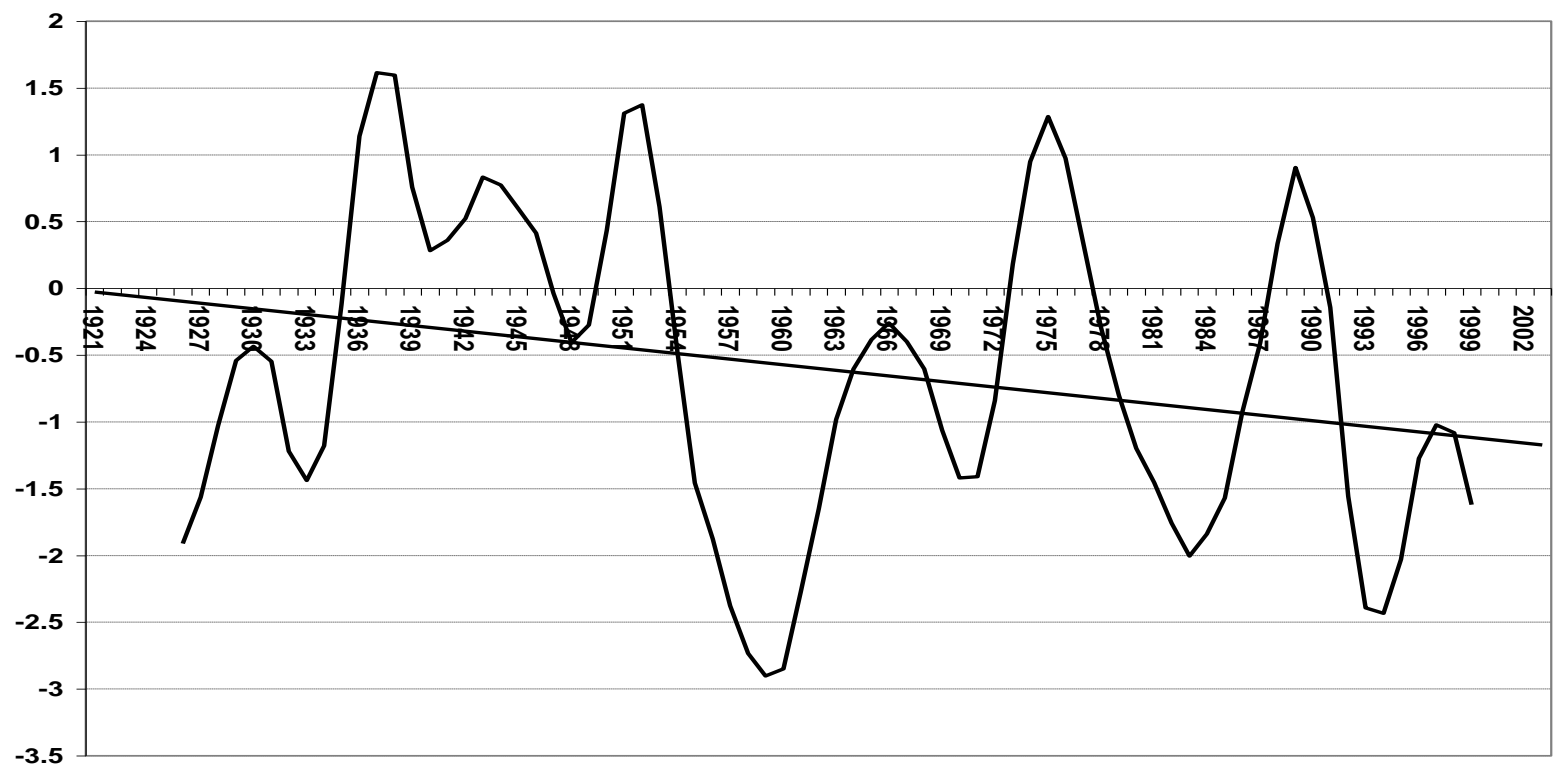

Figure 2a: Smoothed inter-annual MAM rainfall anomalies for Voi in Kenya

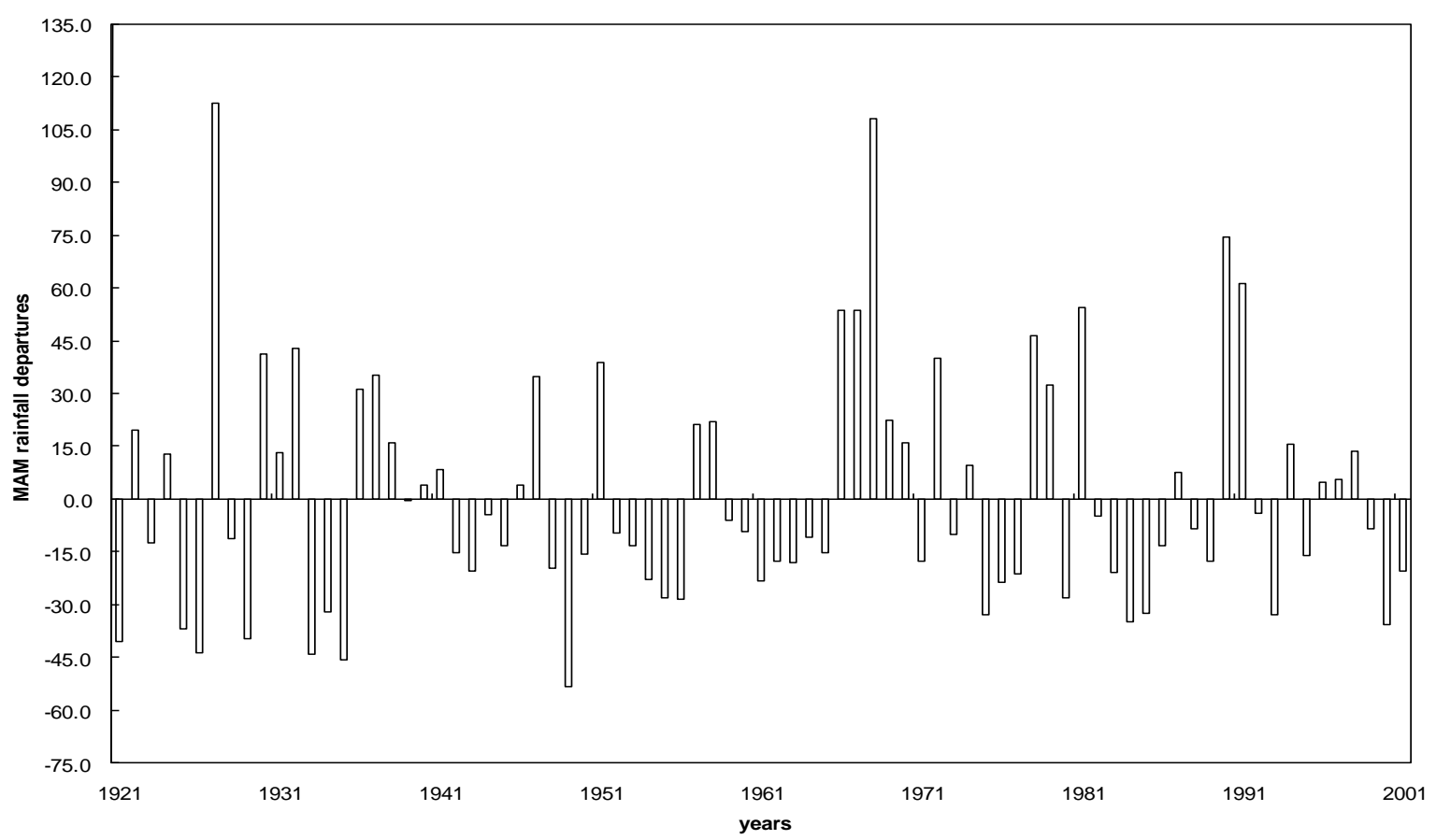

557

558 Figure 2b: Unsmoothed inter-annual MAM rainfall anomalies for Voi in Kenya 


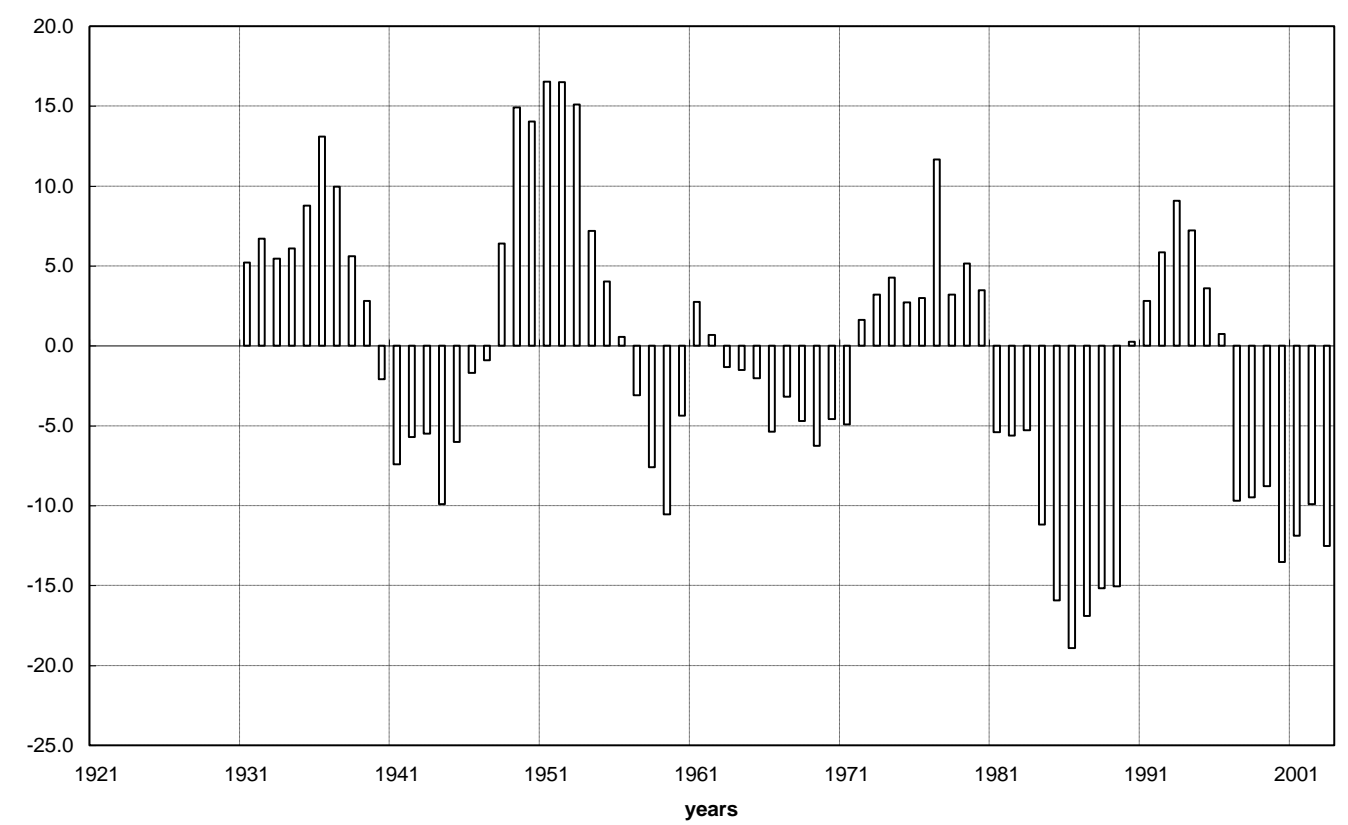

Figure 3a: Graphical plot of the smoothed anomalies for OND decadal rainfall variability 561 over Eastern Africa

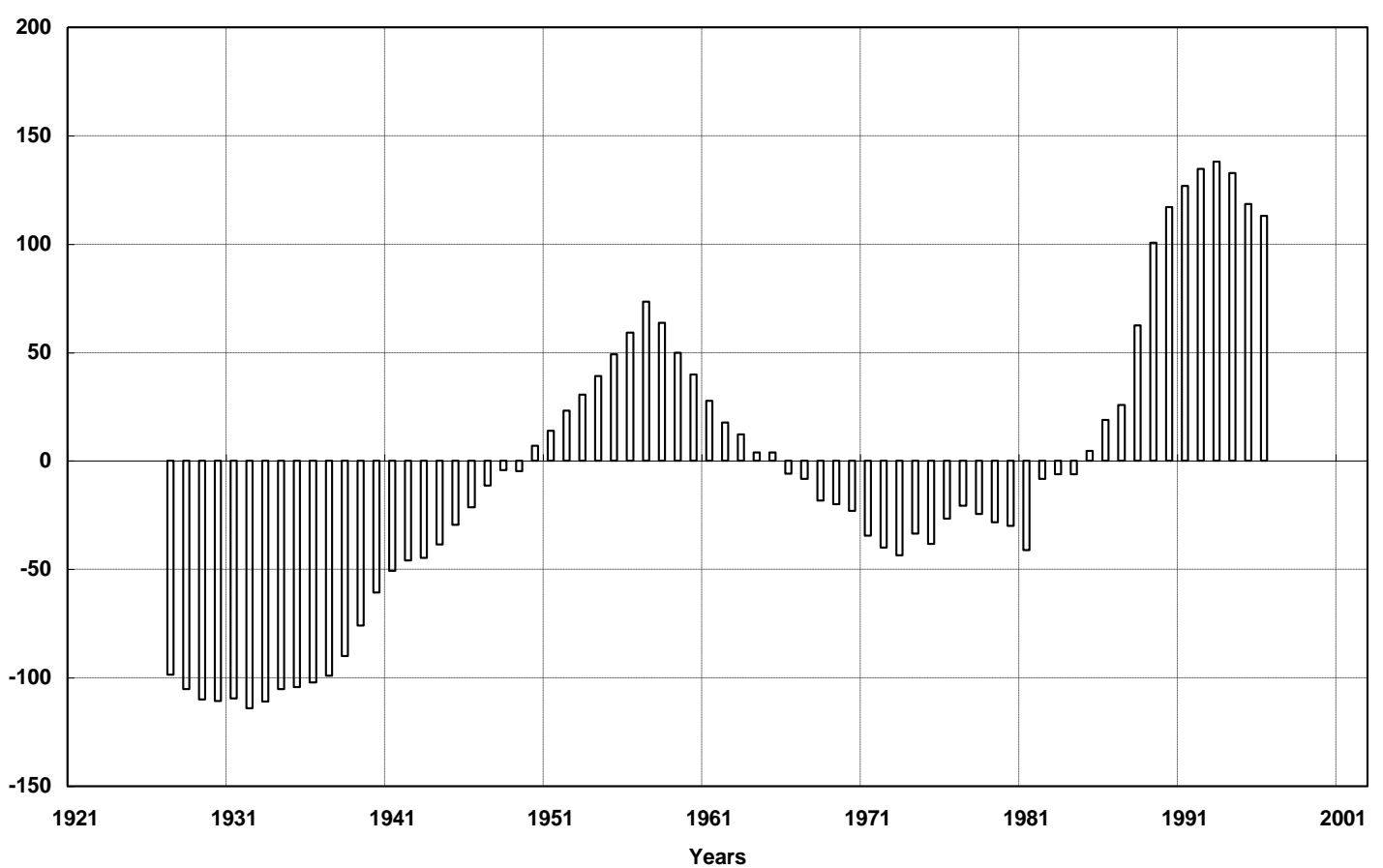

563 Figure 3b: Graphical plot of the smoothed anomalies for JJA decadal rainfall variability over western and coastal sub-regions 


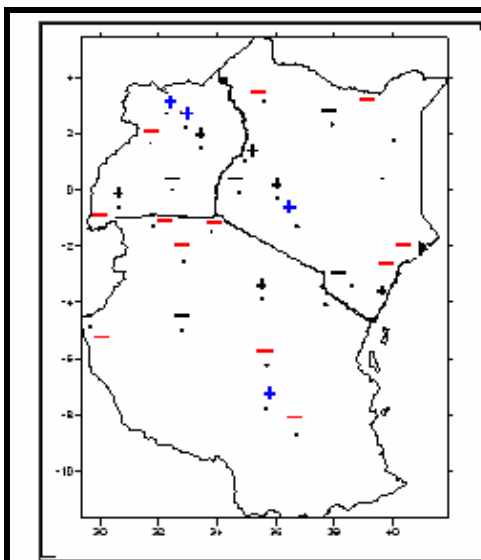

(i) MAM 1921-1930

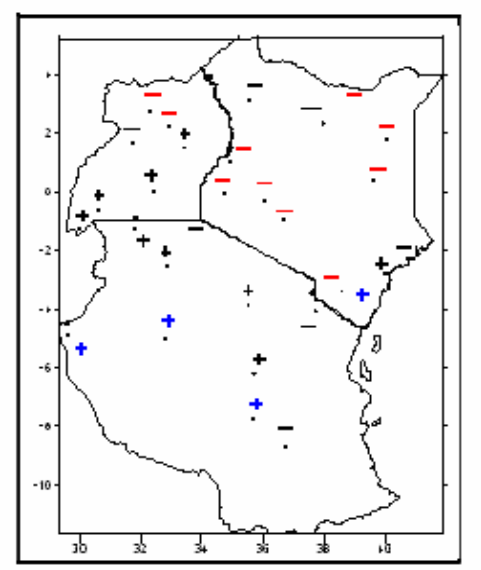

(iii) MAM 1941-1950

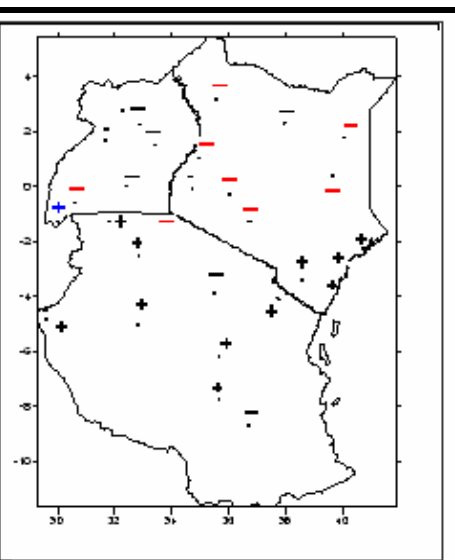

(ii) MAM 1931-1940

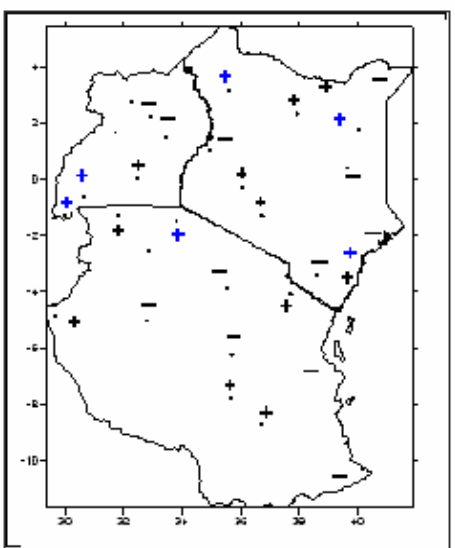

(iv) MAM 1951-1960
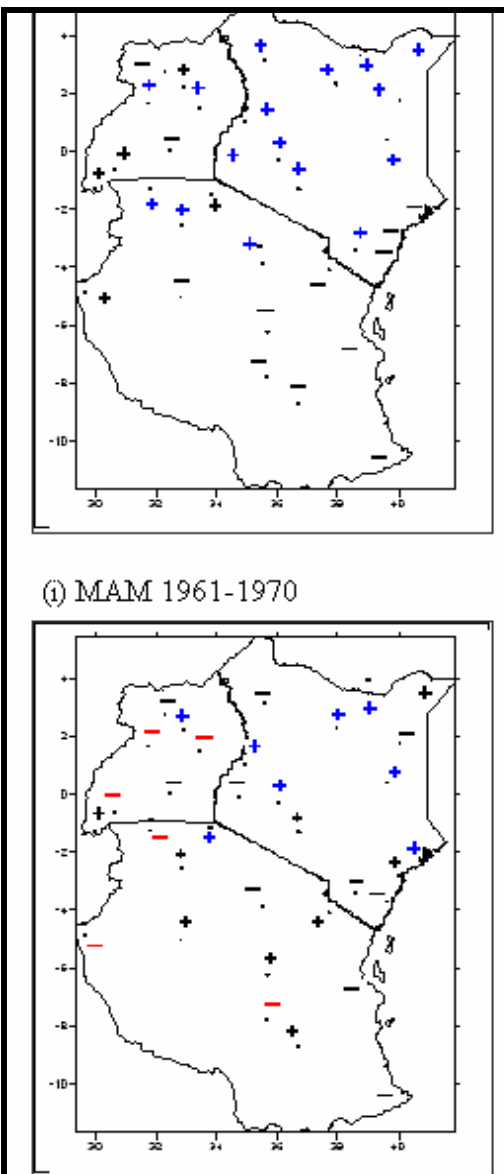

(iii) MAM 1981-1990

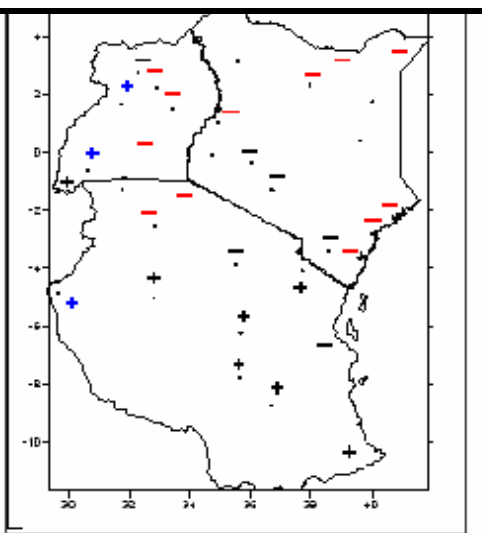

(ii) MAM 1971-1980

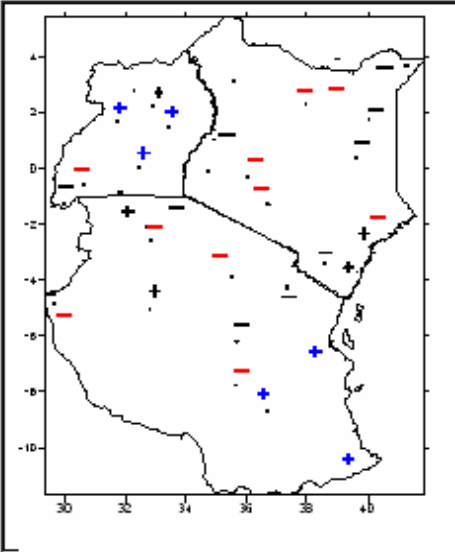

(iv) MAM 1991-2000

\section{Figure 4: Spatial distribution of the mean decadal rainfall for MAM}

- Blue: statistically significant increase in mean decadal rainfall

- Red: statistically significant decrease in mean decadal rainfall

- Black: no significant increase / decrease in mean decadal rainfall 


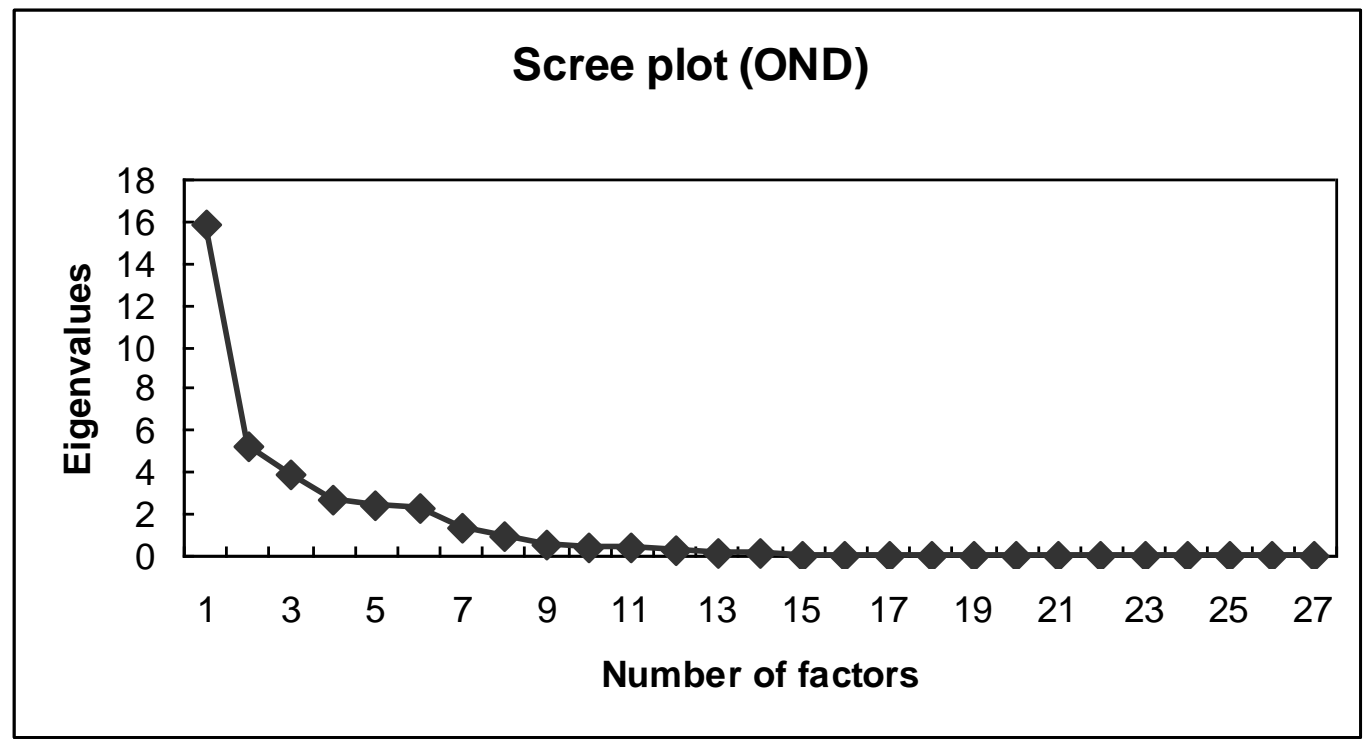

571 Figure 5: Scree's test selection of dominant Principal Components for OND rainfall 572 seasons.

573
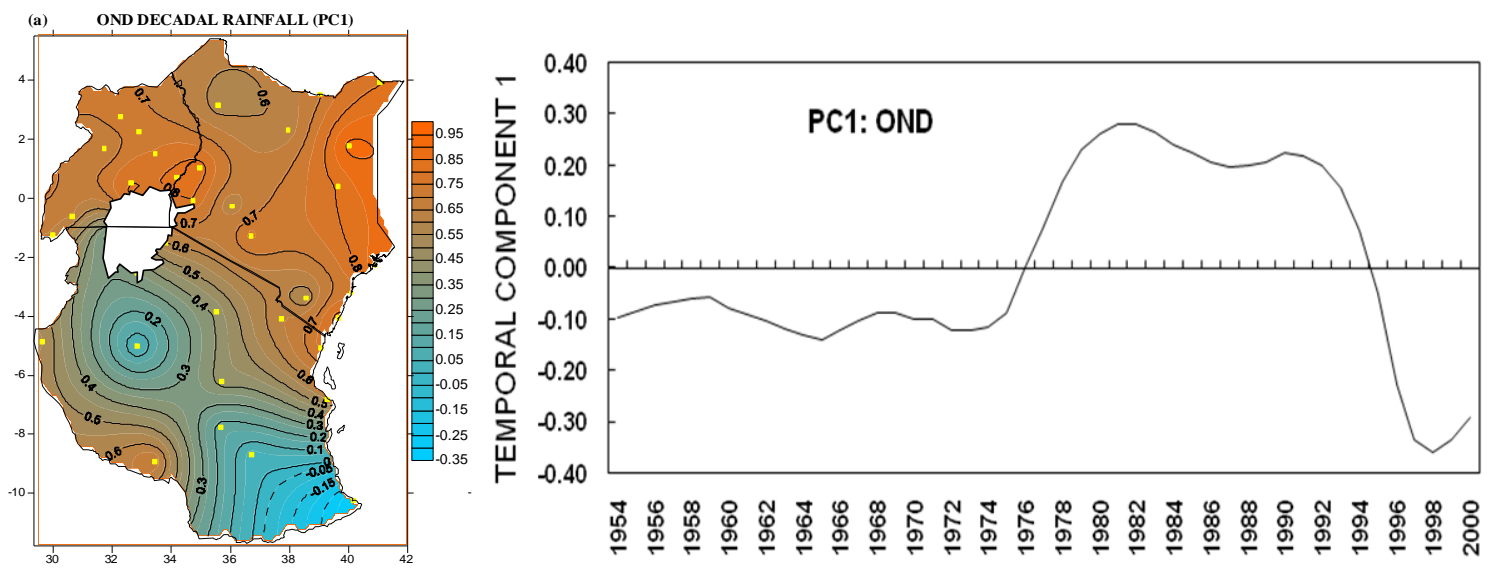

575

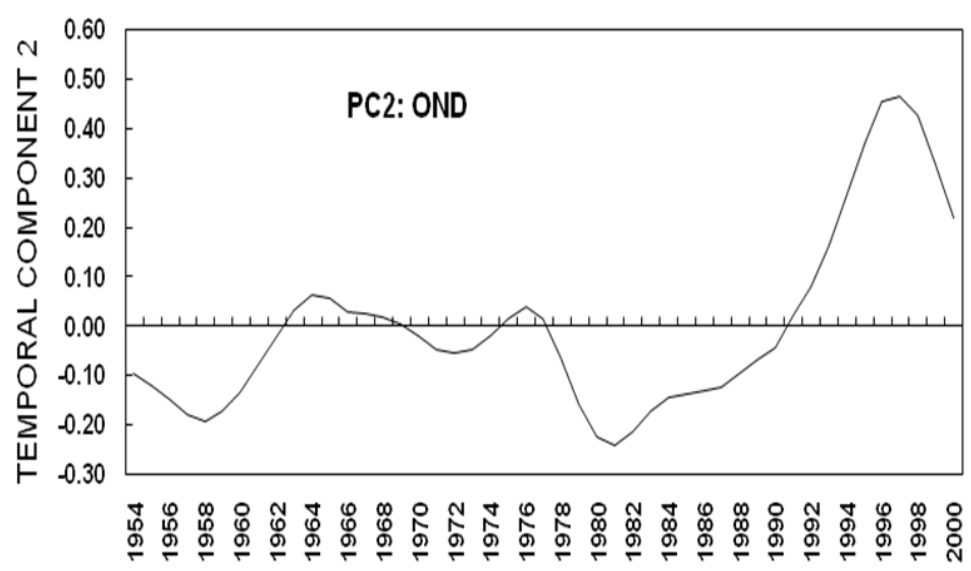



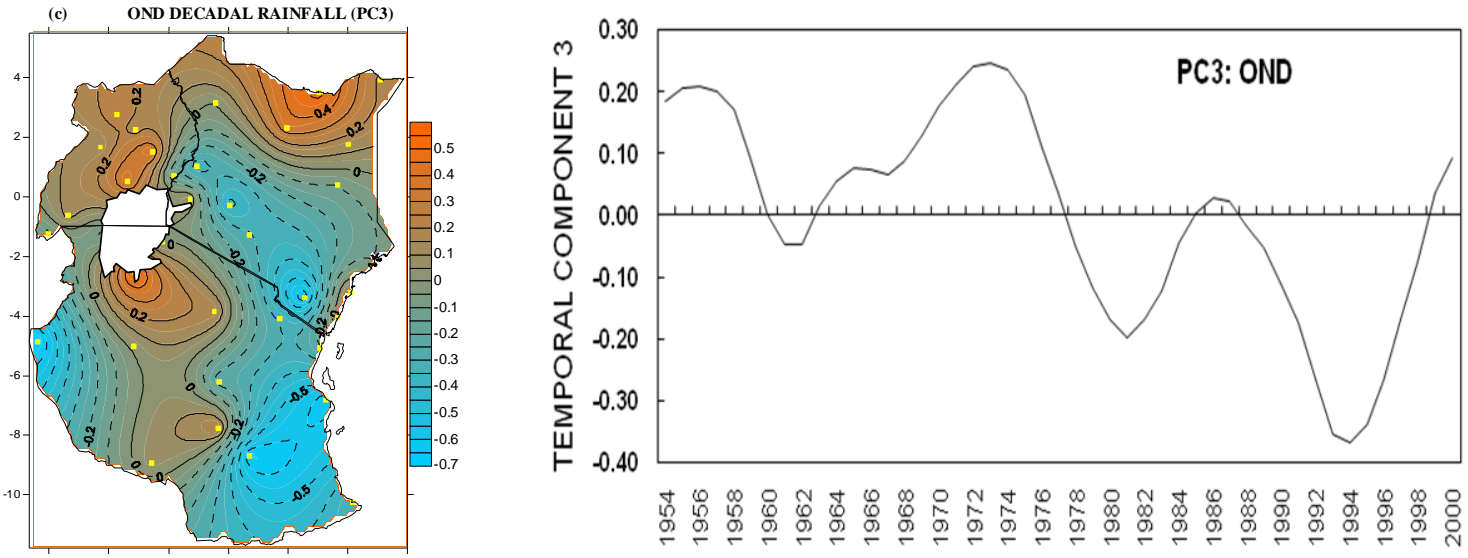

579 Figure 6: Spatial and temporal patterns for EOF1 and PC1 (first row); EOF2 and PC2 (second row) and EOF3 and PC3 (third row) for OND decadal rainfall. Dashed / solid contours represent negative / positive values; contour interval is 0.2 . 


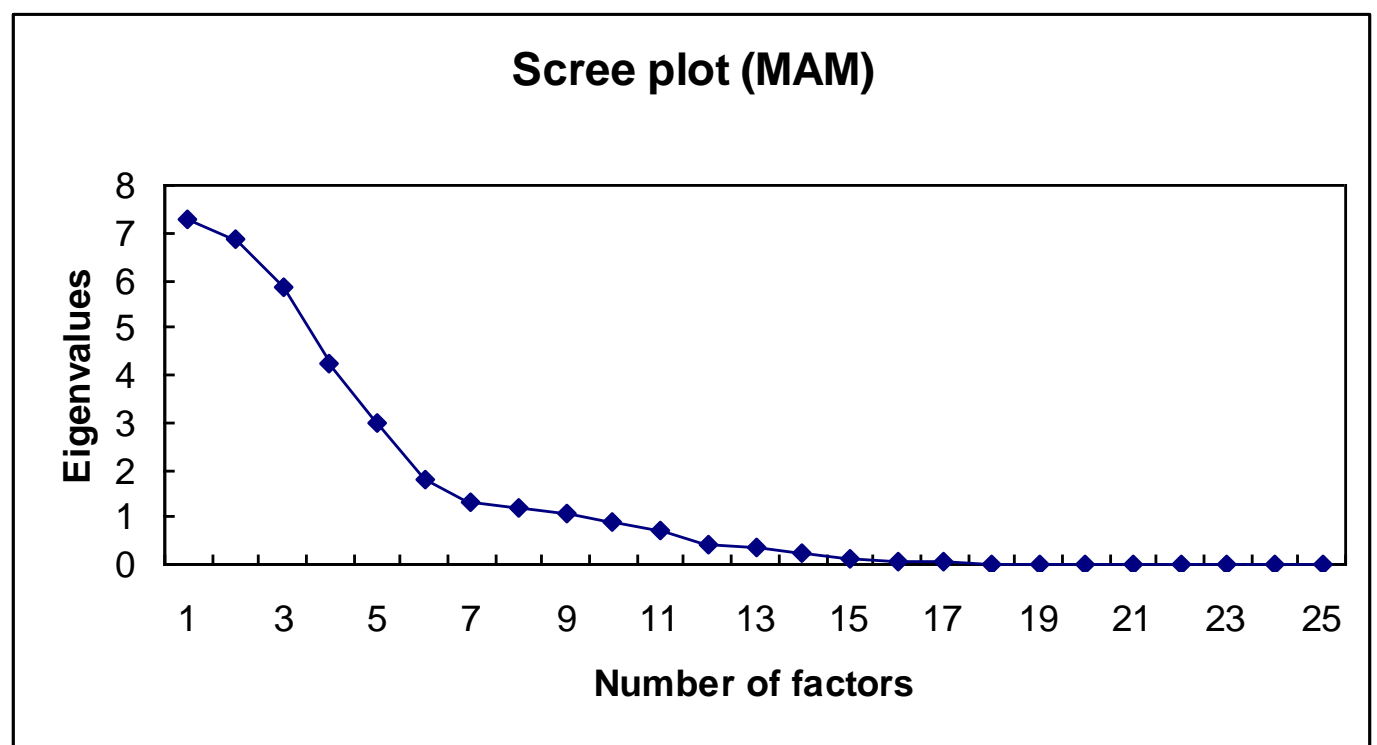

Figure 7: Scree's test selection of dominant Principal Components for MAM rainfall 584 seasons 
(a) MAM DECADAL RAINFALL (PC 1)

586

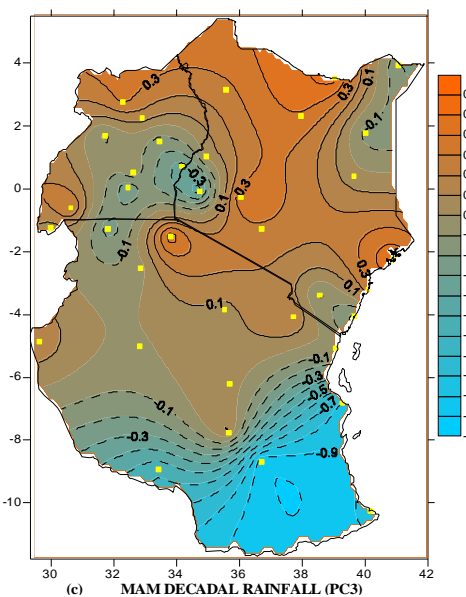

587

588

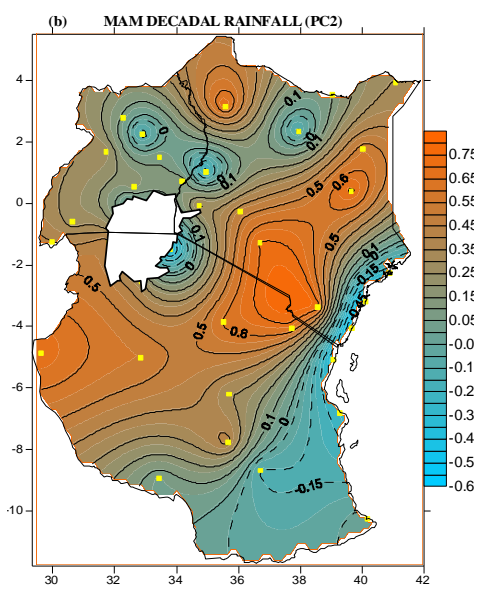

589

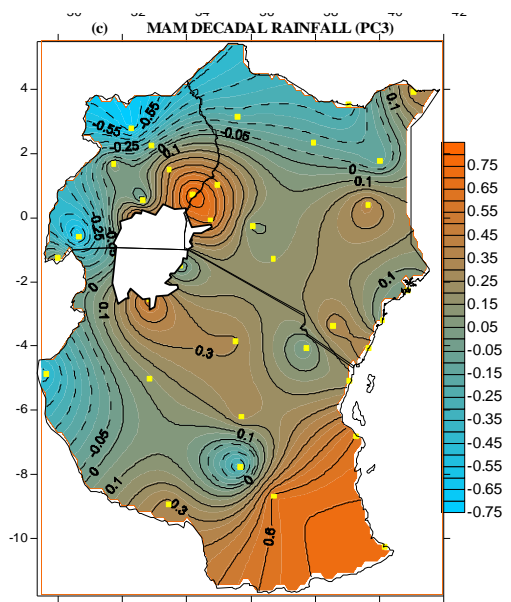

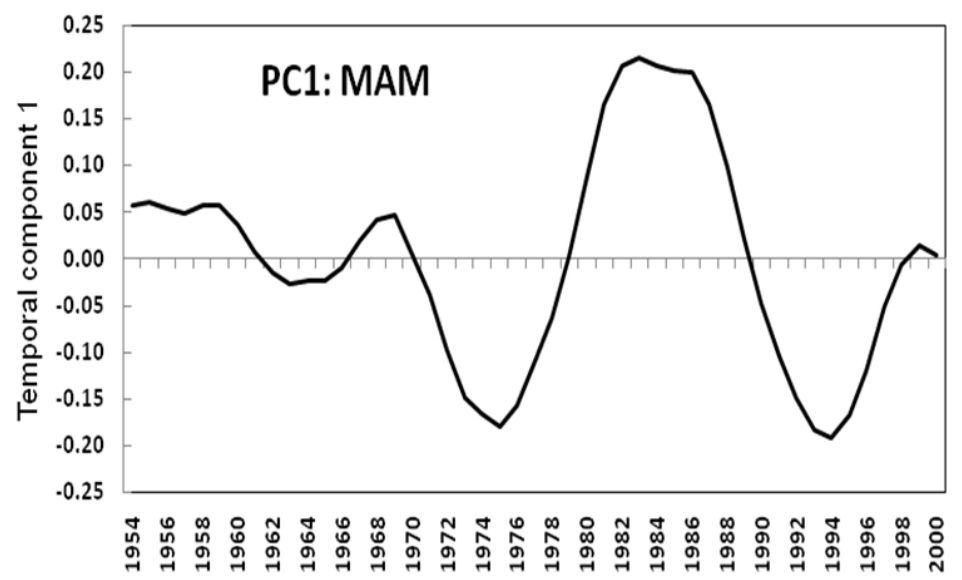
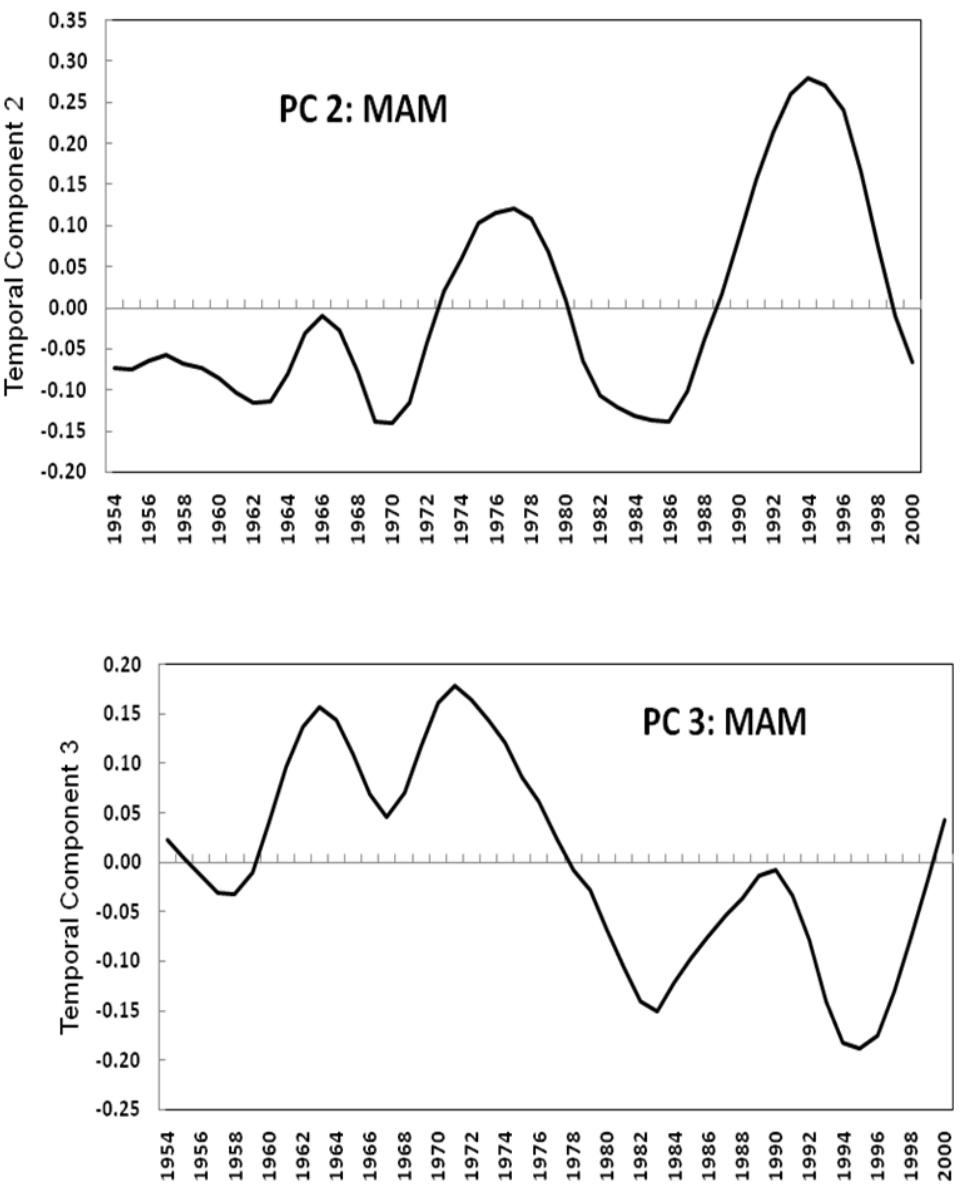

Figure 8: Same as Figure 6 but for MAM decadal rainfall. 


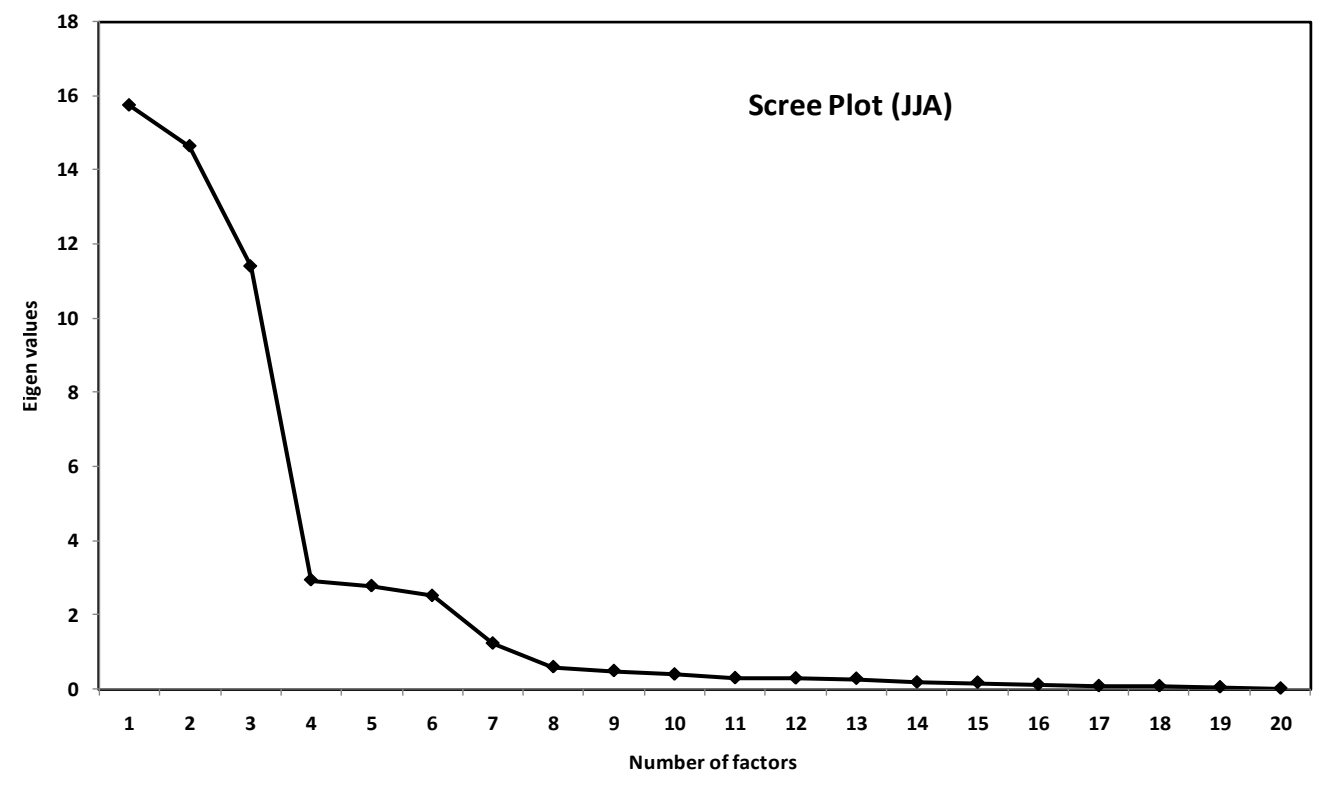

592 Figure 9: Scree's test selection of dominant Principal Components for June-July rainfall 593 seasons. 

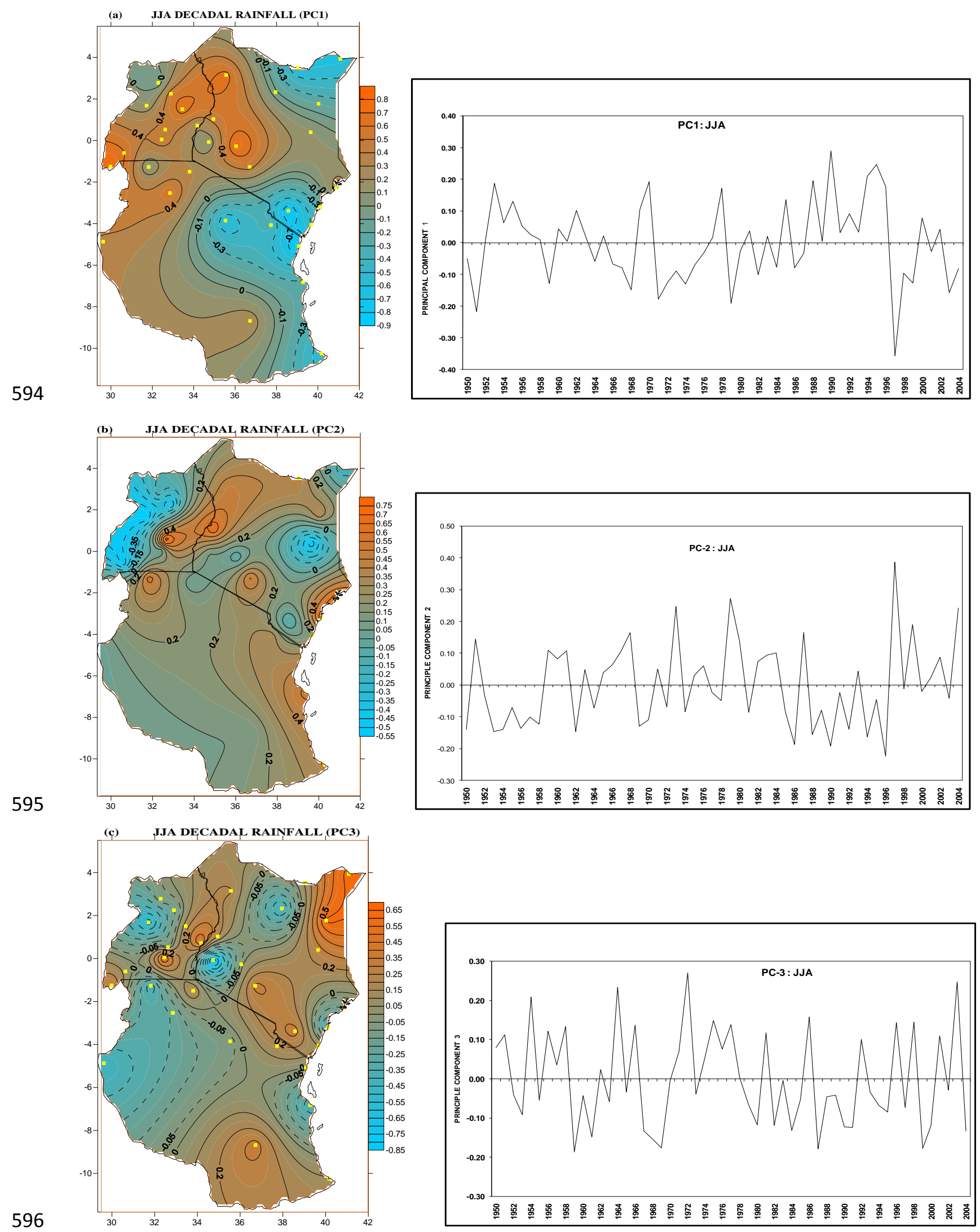

597 Figure 10: Same as Figure 6 but for JJA decadal rainfall. 


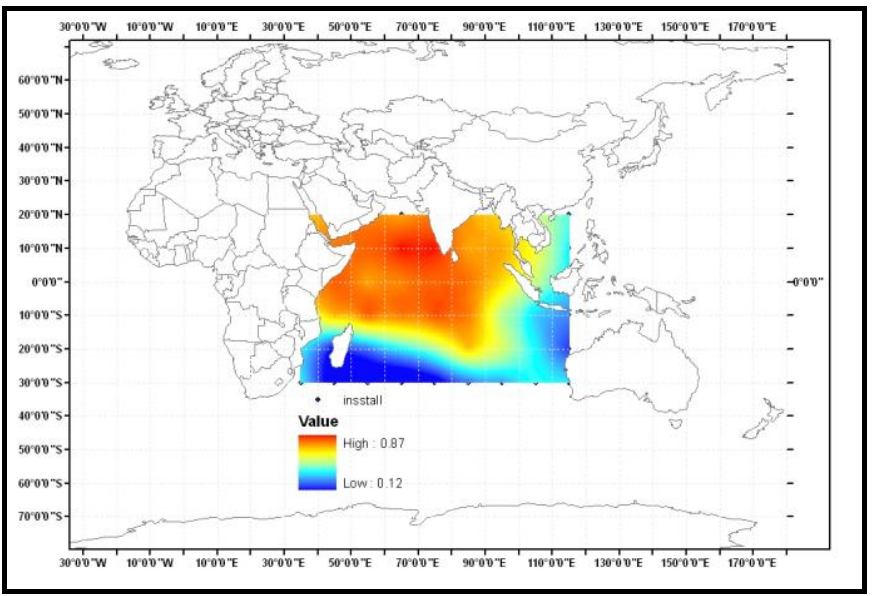

(a) Indian Ocean October - December (OND) PC1

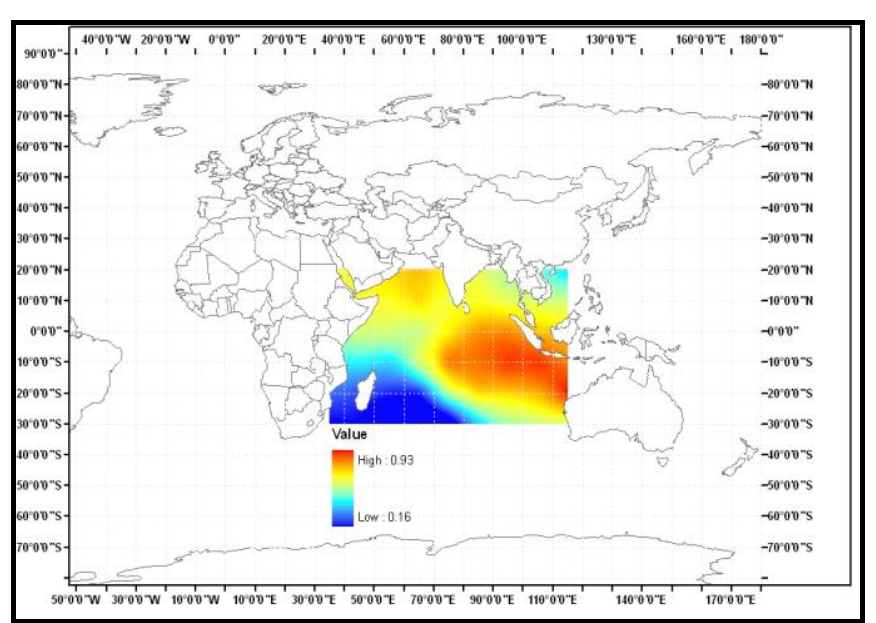

(c) Indian Ocean March - May (MAM) PC1

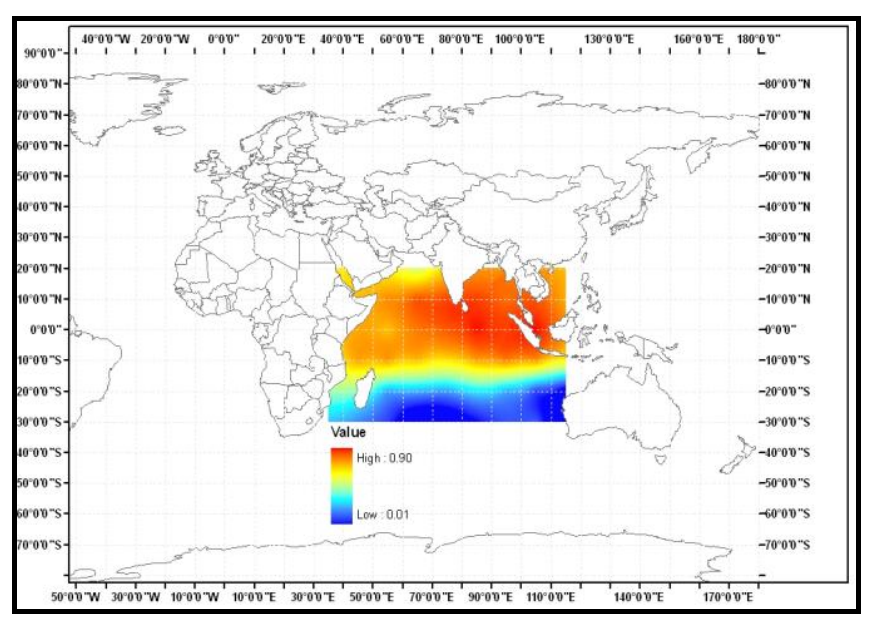

(b) Indian Ocean December - February (DJF) PC1

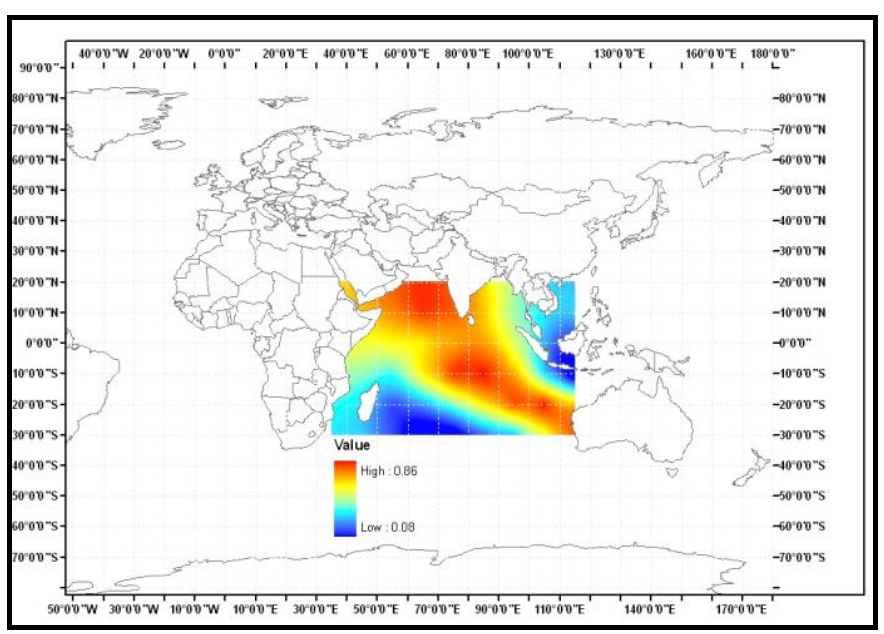

(d) Indian Ocean June - August (JJA) PC1

Figure 11: The spatial patterns of the first 9-term binomial coefficient filtered SST PCA modes for the Indian Ocean. 


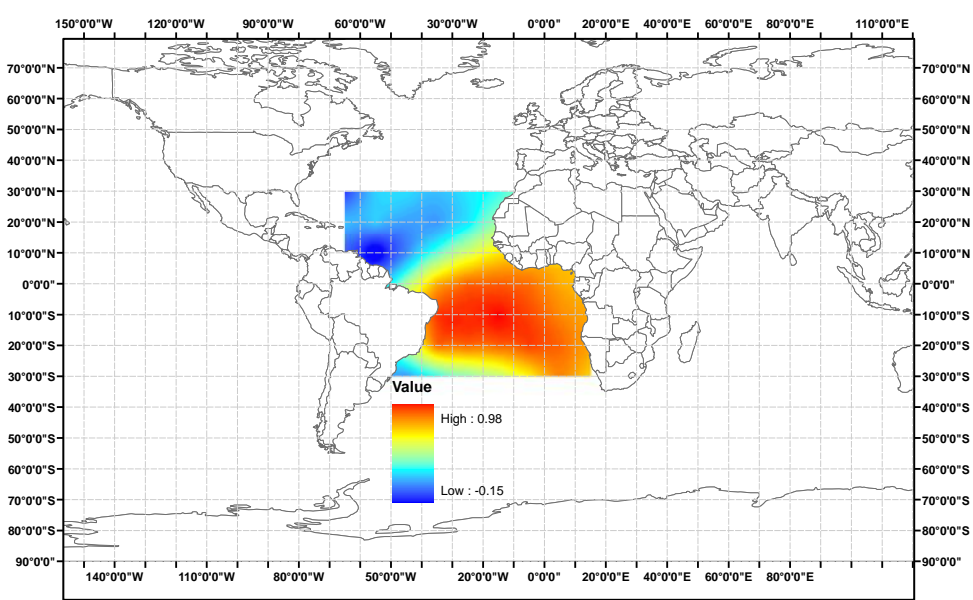

605 (a) Atlantic Ocean October-December PC1

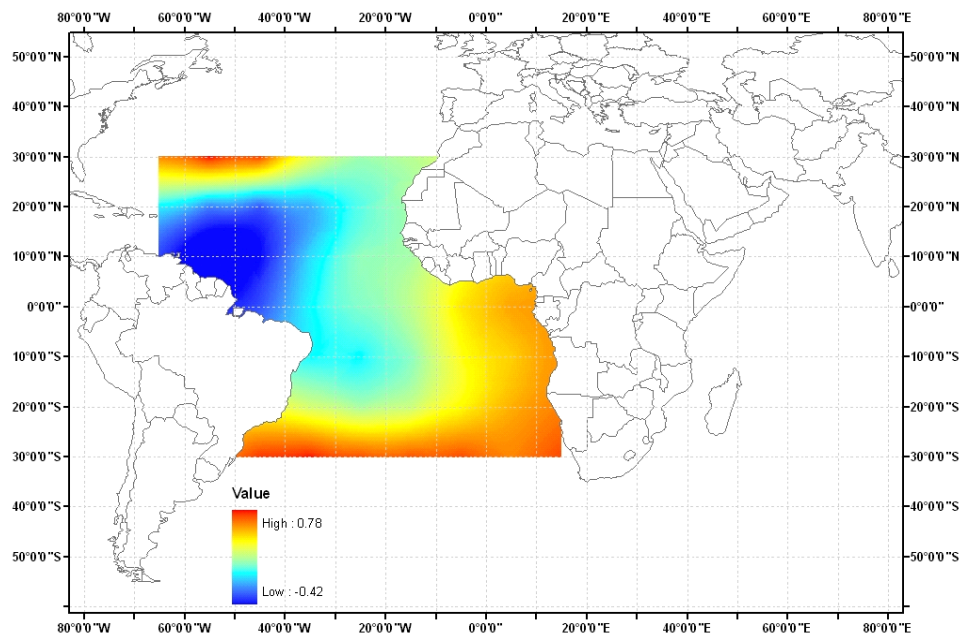

(c) Atlantic Ocean March-May PC1

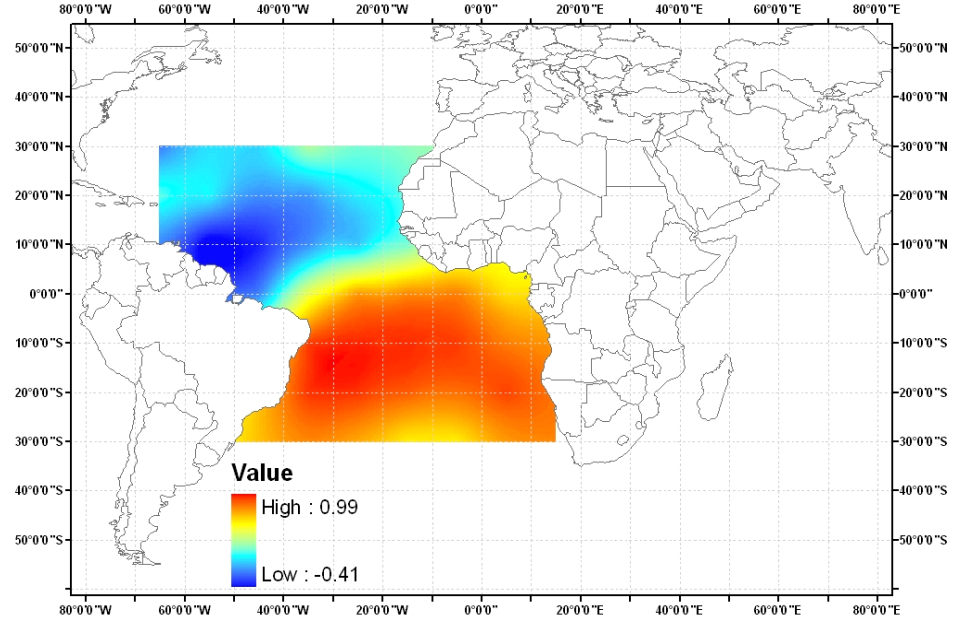

(b) Atlantic Ocean December-February PC1

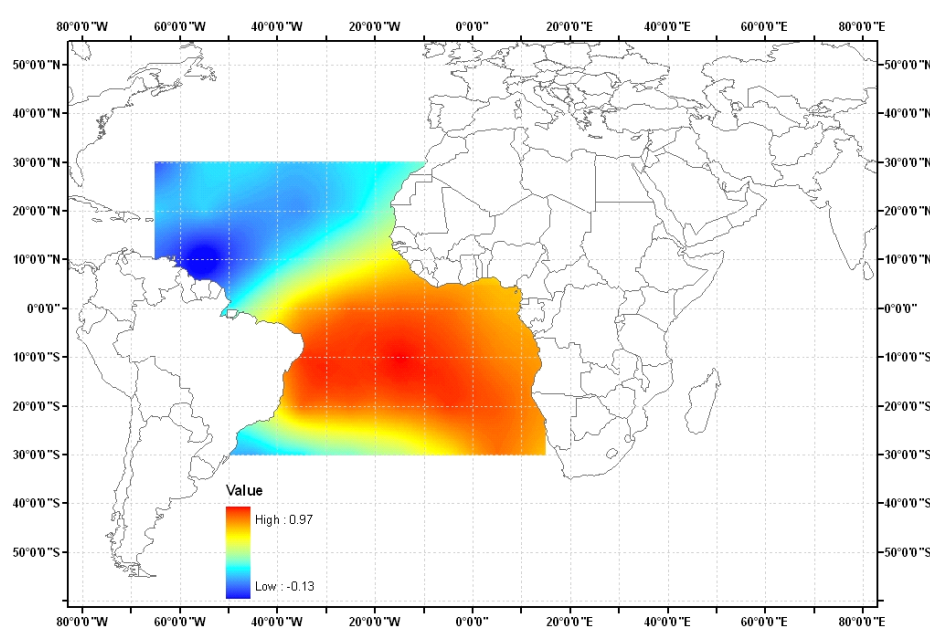

(d) Atlantic Ocean June-August PC1

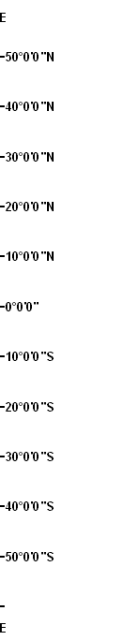

Figure 12: The spatial patterns of the first 9-term binomial coefficient of the filtered SST PCA modes for the Atlantic Ocean. 


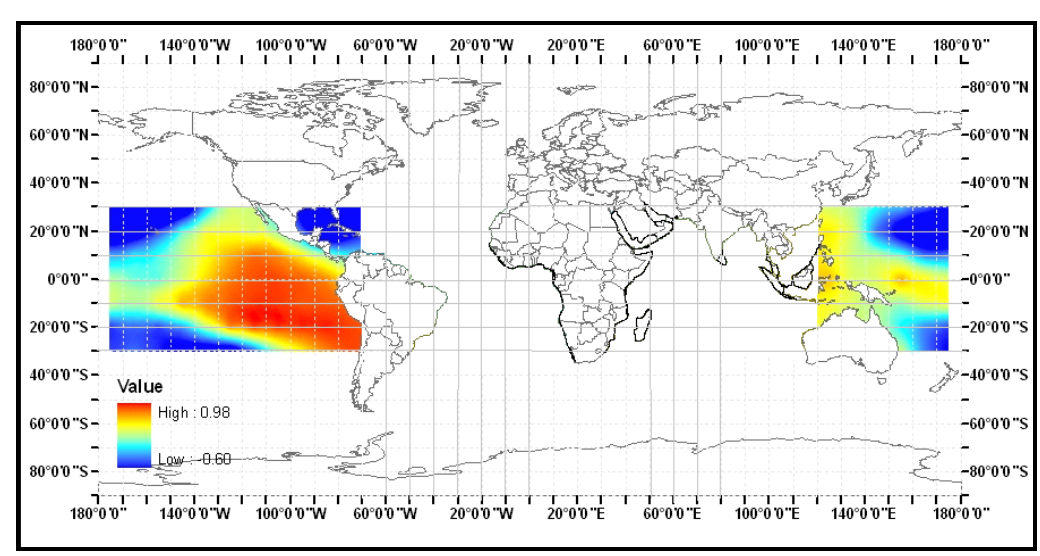

611

(c) Pacific Ocean March-May PC1

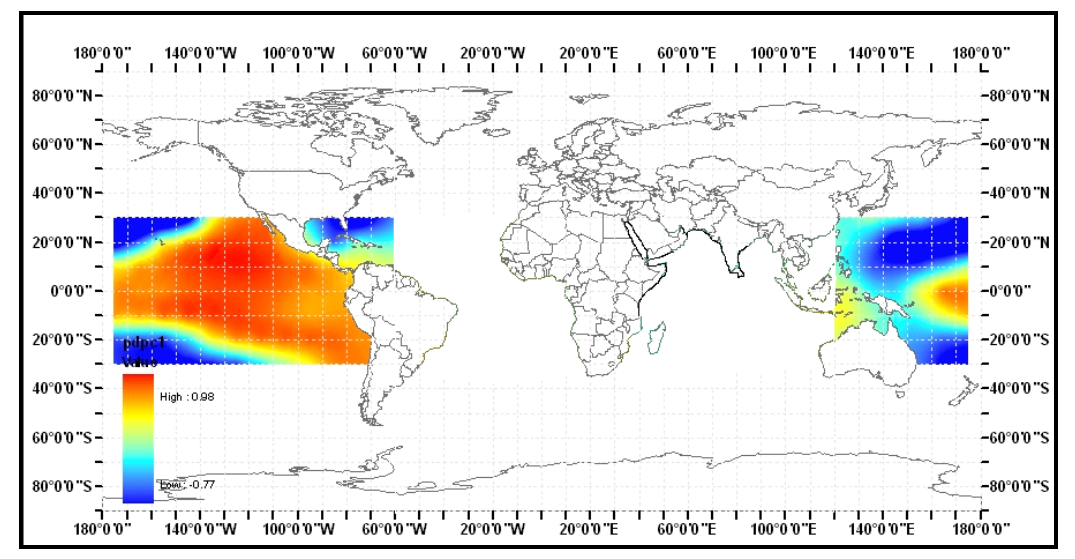

(b) Pacific Ocean December - February PC1

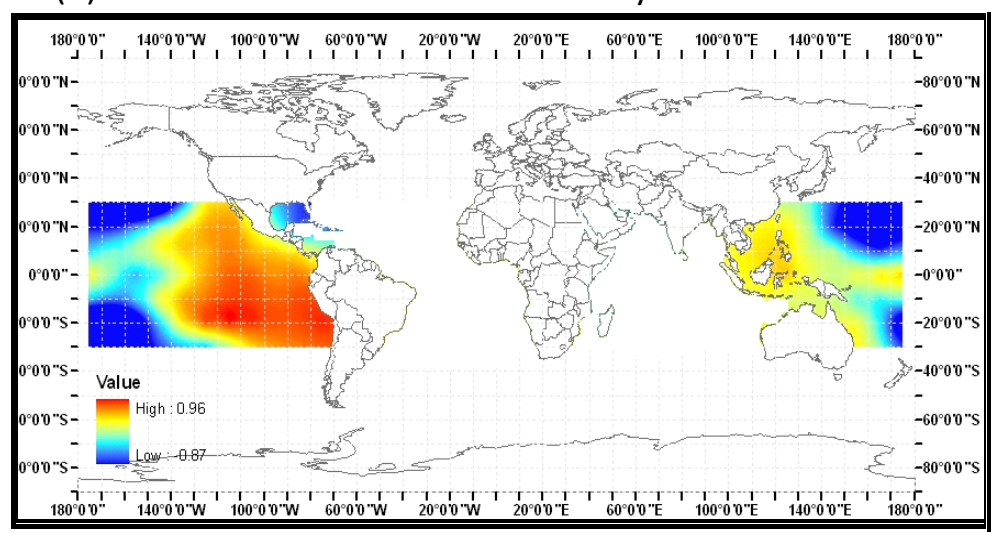

(d) Pacific Ocean June-August PC1

Figure 13: The spatial patterns of the first 9-term binomial coefficient filtered SST PCA modes for the Pacific Ocean 


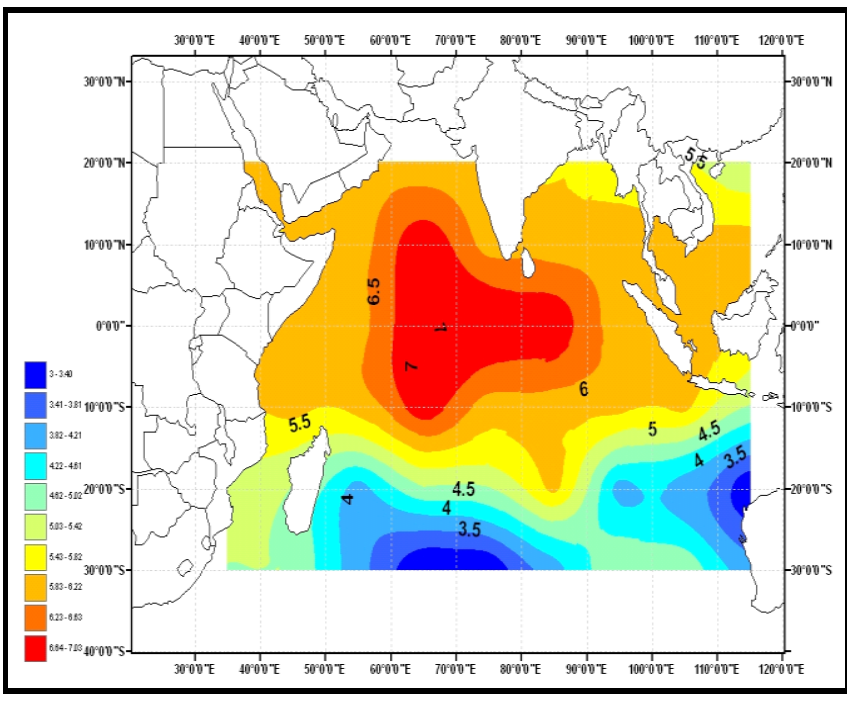

616

(a) CCA-1 December-February SST

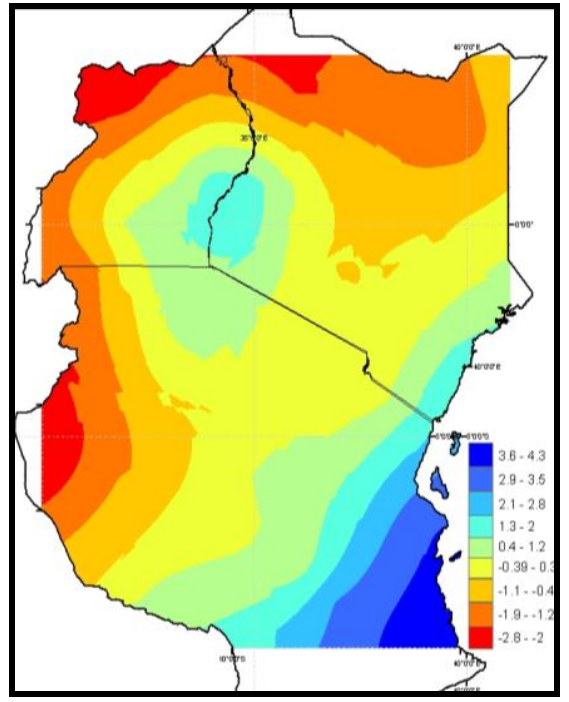

(b) CCA-1 MAM Rainfall

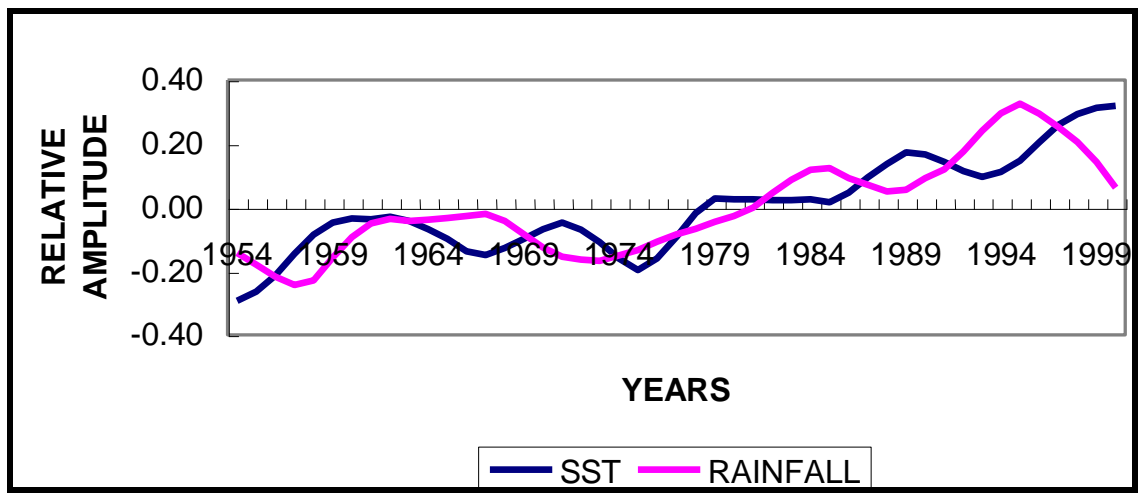

(c) CCA MODE1 (CORRELATION = -0.79)

619 Figure 14: The first spatial pattern pair for canonical correlation between decadal DJF of the Indian SST and MAM rainfall ;(a) correlation between the predictor (SST) and the canonical vector $(\mathrm{u})$; (b) correlation between the predictant (rainfall) and canonical vector (v) and; (c) normalized temporal functions ( $u$ and $v$ ) of the first CCA patterns for rainfall and SST 


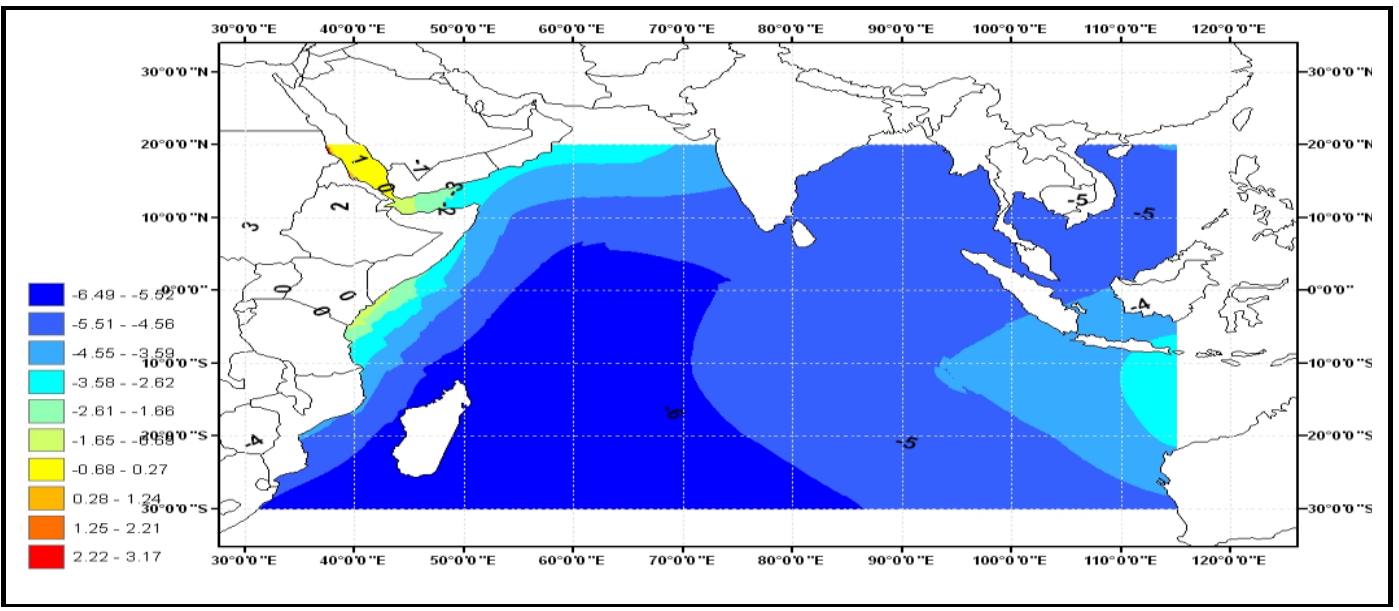

625

626

(a) CCA-1 March - May SST

627

628

629

630

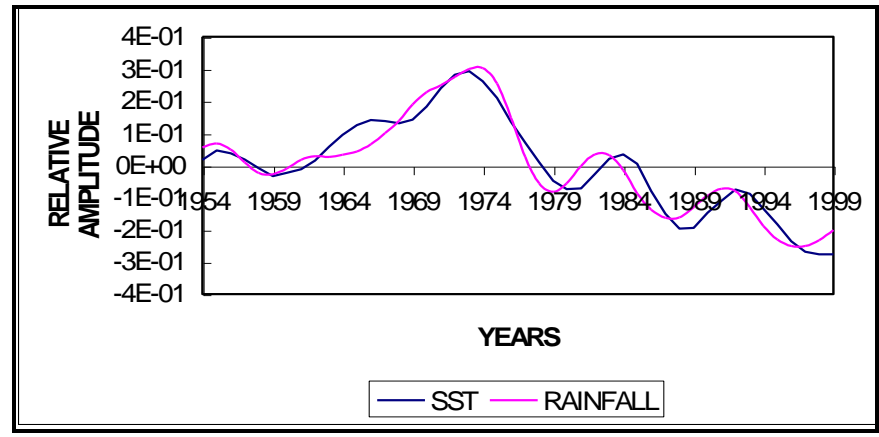

(c) CCA Model (Correlation 0.96)

(b) CCA-1 March - May Rainfall

Figure 15: Same as Figure 14 but for MAM of the Indian Ocean SST (lag zero). 

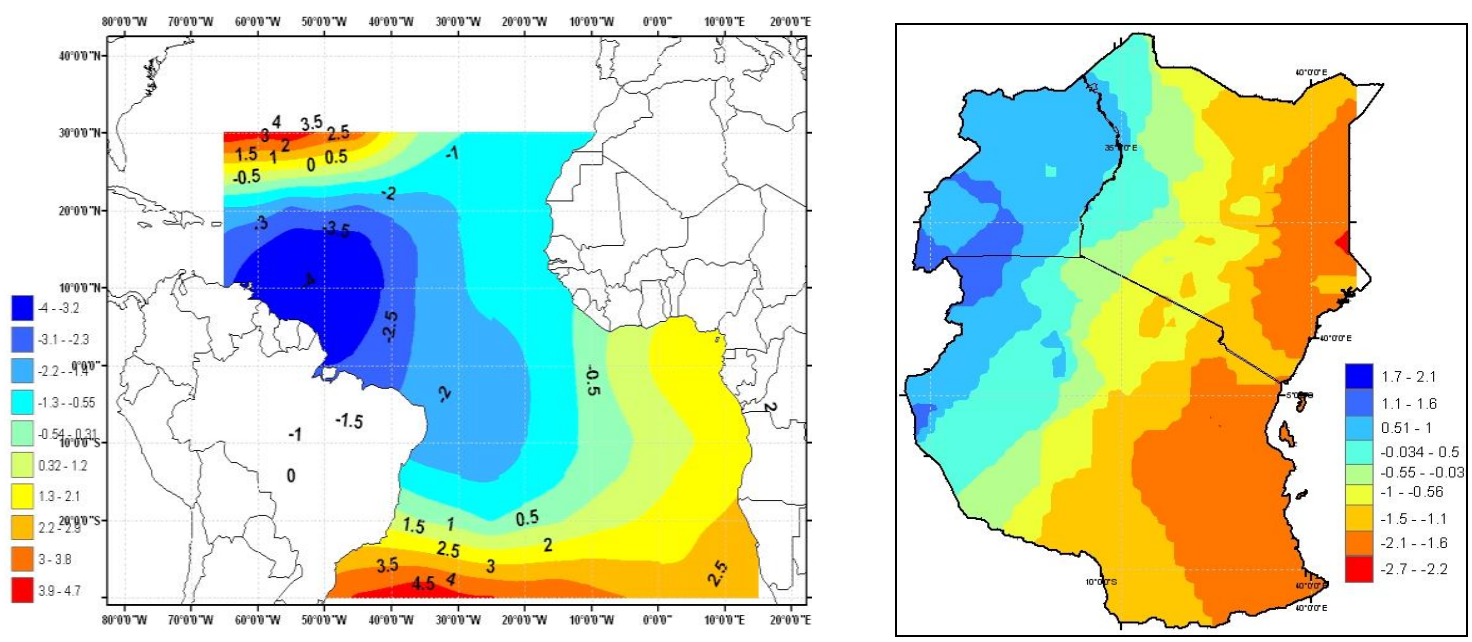

(a) CCA Model 1 (Correlation $=0.72)$

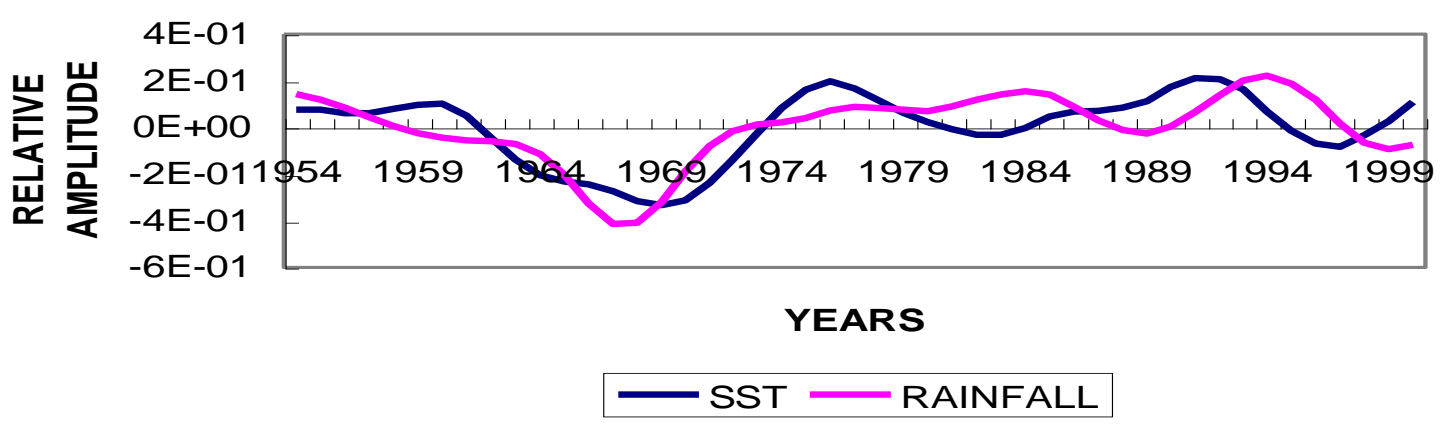

Figure 16: The first spatial pattern pair for canonical correlation between decadal MAM Atlantic SST and JJA rainfall ; (a) correlation between the predictor (SST) and the canonical vector $(\mathrm{u})$; (b) correlation between the predictant (rainfall) and canonical vector (v) and; (c) normalized temporal functions ( $u$ and $v$ ) of the first CCA patterns for rainfall and SST. 


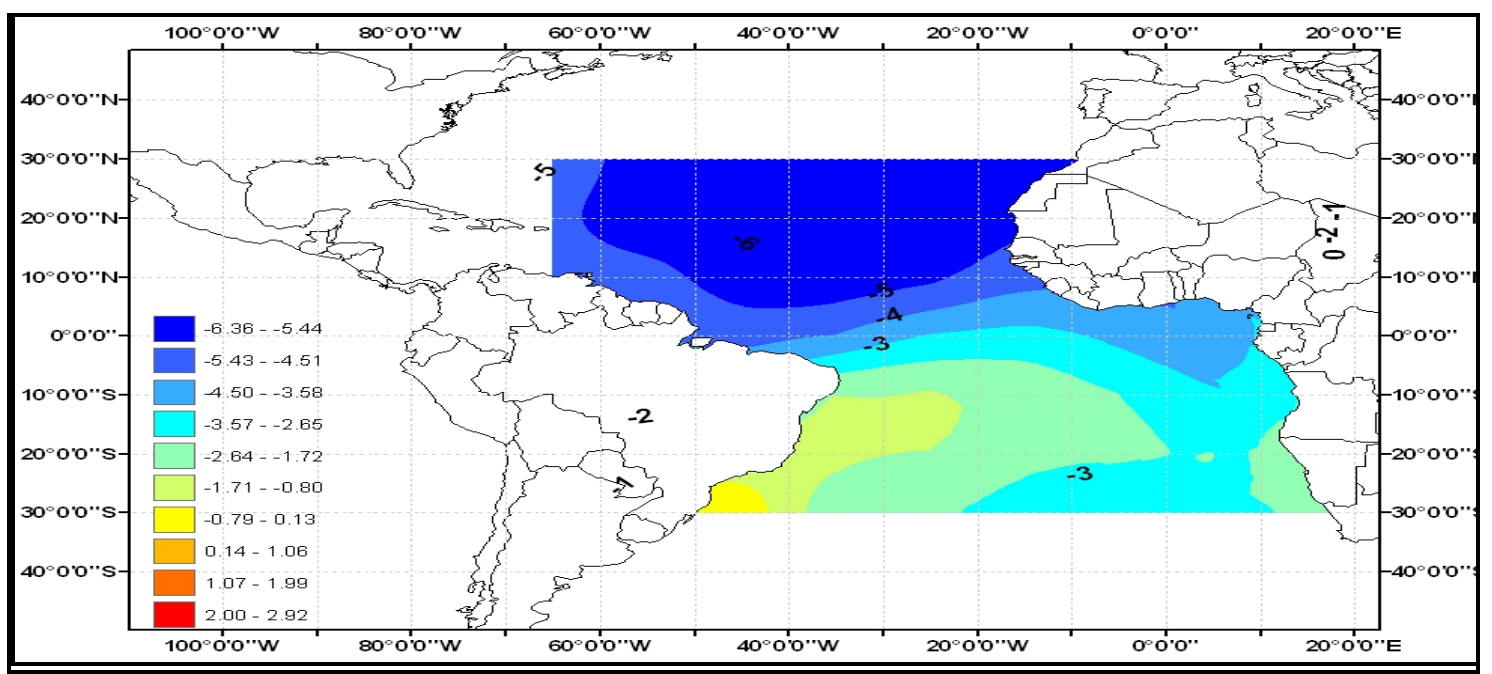

CCA-1 June - August Atlantic Ocean SST

644

645

646

647

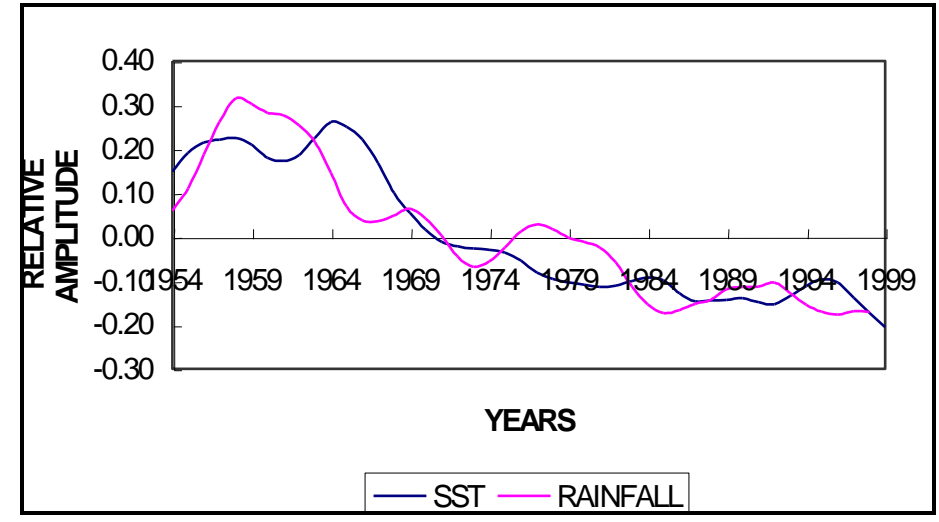

(c) CCA Model $($ Correlation $=0.87$ )

(b) CCA-1 June - August Rainfall

Figure 17: Same as Figure 17 but for JJA SST (lag zero). 
140E l50E l60E l70E 180 l70W l60W 150W l40W 130W 120W 110W 100W 90W 80W

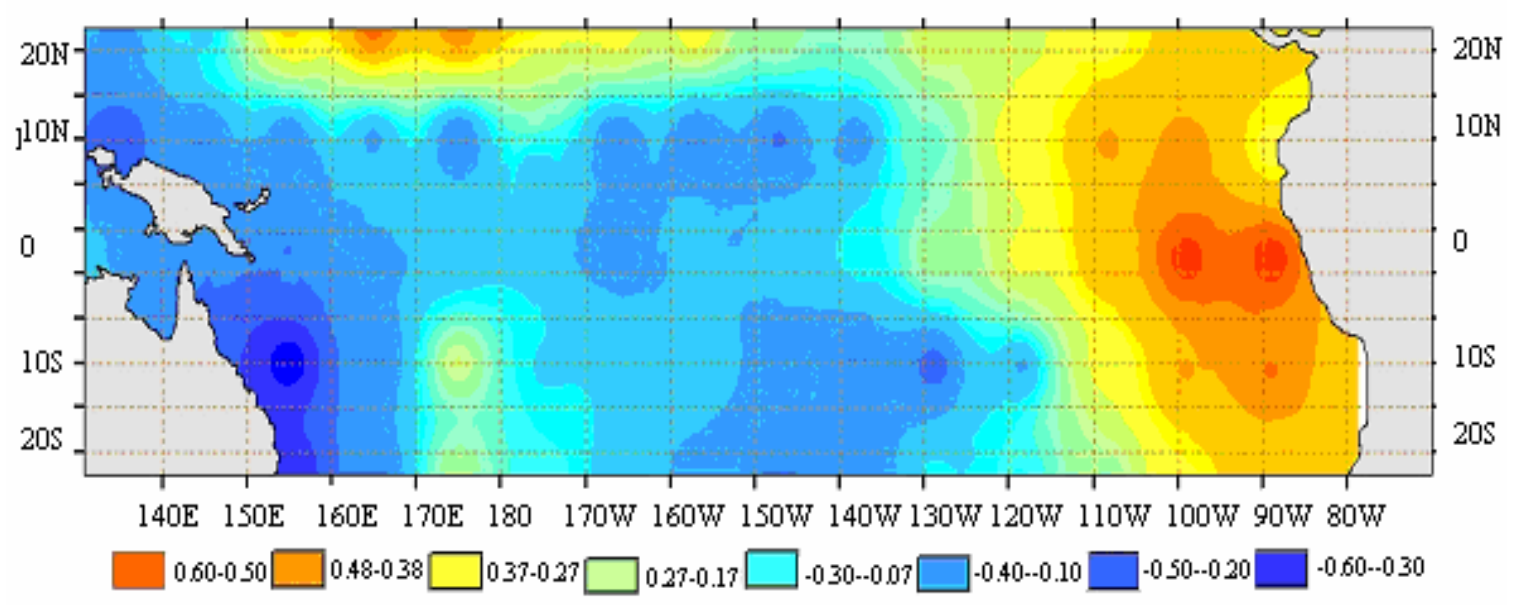

(a) CCA-1 June - August SST

650

651

652

653

654

655

656

657

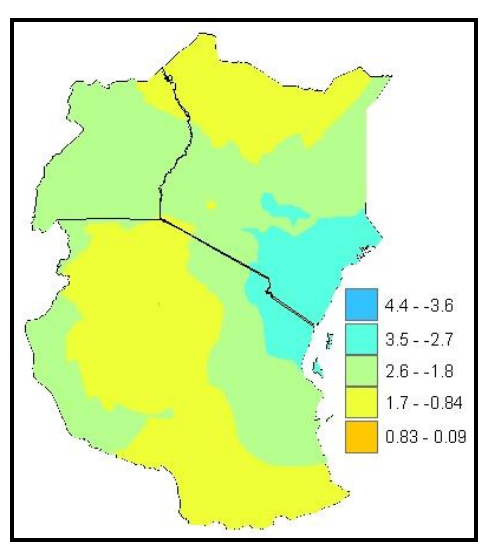

(b) CCA-1 October-December Rainfall

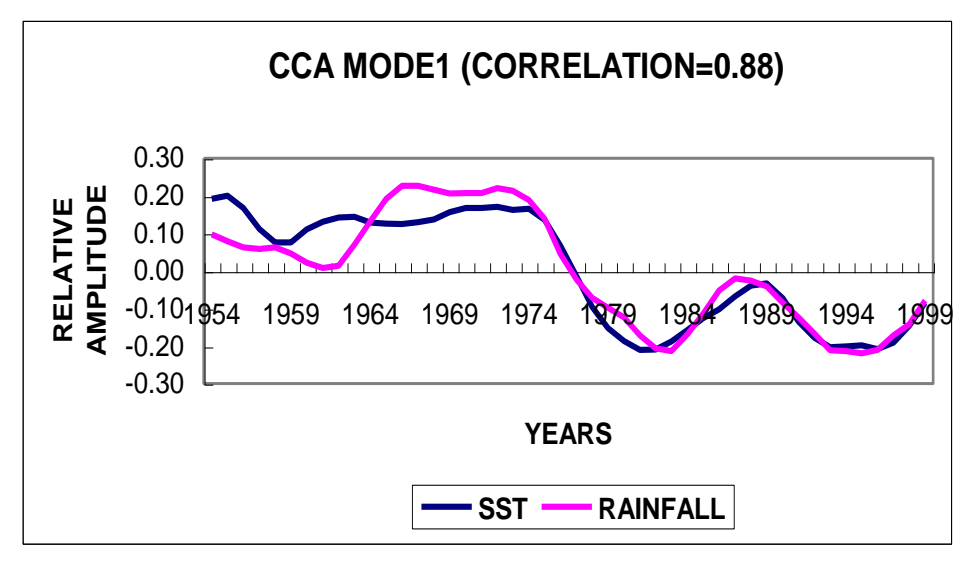

(c) CCA MODE1 (CORRELATION=0.88)

Figure 18: The first spatial pattern pair for canonical correlation between decadal JJA Pacific SST and OND rainfall; (a) correlation between the predictor (SST) and the canonical vector $(\mathrm{u})$; (b) correlation between the predictant (rainfall) and canonical vector (v) and; (c) normalized temporal functions ( $u$ and $v$ ) of the first CCA patterns for rainfall and SST. 


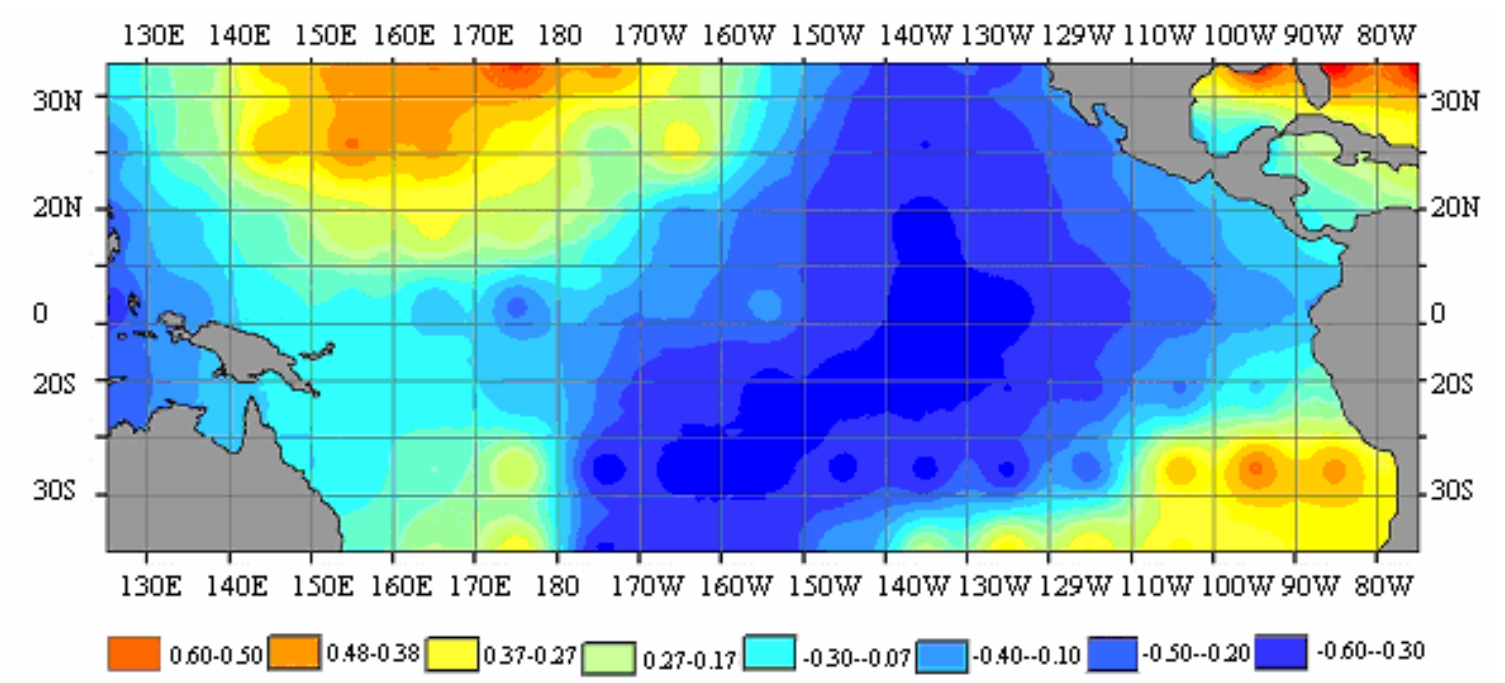

658

659 (a) CCA-1 October-December SST

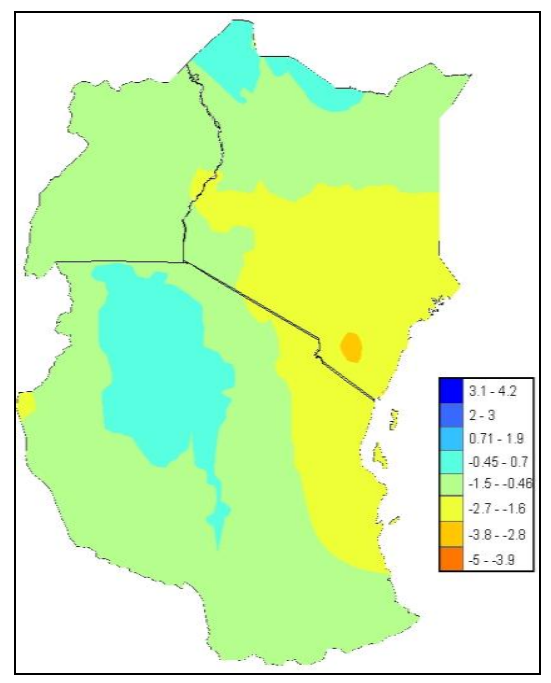

(b) CCA-1 OND Rainfall

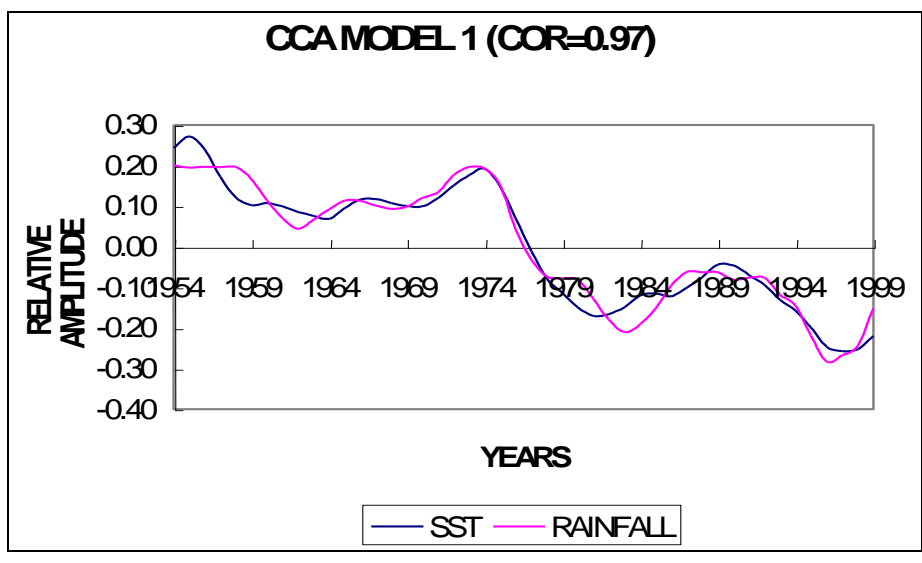

(c) CCA MODEL (CORRELATION $=0.97)$

661

Figure 19: Same as Figure 19 but for OND SST (lag zero).

663

664

665

666 